This is a self-archived version of an original article. This version may differ from the original in pagination and typographic details.

Author(s): Verma, Anand M.; Laverdure, Laura; Melander, Marko M.; Honkala, Karoliina

Title: Mechanistic Origins of the pH Dependency in Au-Catalyzed Glycerol Electro-oxidation : Insight from First-Principles Calculations

Year: 2022

Version: Published version

Copyright: (c) 2021 the Authors

Rights: $C C B Y 4.0$

Rights url: https://creativecommons.org/licenses/by/4.0/

Please cite the original version:

Verma, A. M., Laverdure, L., Melander, M. M., \& Honkala, K. (2022). Mechanistic Origins of the pH Dependency in Au-Catalyzed Glycerol Electro-oxidation : Insight from First-Principles Calculations. ACS Catalysis, 12(1), 662-675. https://doi.org/10.1021/acscatal.1c03788 


\title{
Mechanistic Origins of the pH Dependency in Au-Catalyzed Glycerol Electro-oxidation: Insight from First-Principles Calculations
}

\author{
Anand M. Verma, Laura Laverdure, Marko M. Melander, and Karoliina Honkala* \\ Cite This: ACS Catal. 2022, 12, 662-675 \\ Read Online
}

ABSTRACT: Electrocatalytic oxidation of glycerol (EOG) is an attractive approach to convert surplus glycerol to value-added products. Experiments have shown that EOG activity and selectivity depend not only on the electrocatalyst but also on the electrode potential, the $\mathrm{pH}$, and the electrolyte. For broadly employed gold $\mathrm{(Au}$ ) electrocatalysts, experiments have demonstrated high EOG activity under alkaline conditions with glyceric acid as a primary product, whereas under acidic and neutral conditions $\mathrm{Au}$ is almost inactive producing only small amounts of dihydroxyacetone. In the present computational work, we have performed an extensive mechanistic study to understand the $\mathrm{pH}$ and potential dependency of

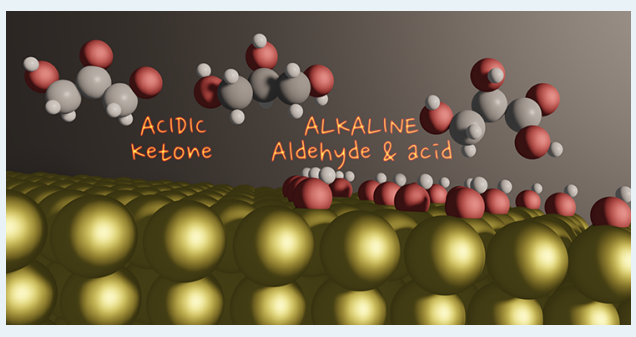
Au-catalyzed EOG. Our results show that activity and selectivity are controlled by the presence of surface-bound hydroxyl groups. Under alkaline conditions and close to the experimental onset potential, modest $\mathrm{OH}$ coverage is preferred according to our constant potential calculations. This indicates that both $\mathrm{Au}(\mathrm{OH})_{\text {ads }}$ and $\mathrm{Au}$ can be active sites and they cooperatively facilitate the thermodynamically and kinetically feasible formation of glyceric acid thus explaining the experimentally observed high activity and selectivity. Under acidic conditions, hydroxide coverage is negligible and the dihydroxyacetone emerges as the favored product. Calculations predict slow reaction kinetics, however, which explains the low activity and selectivity toward dihydroxyacetone reported in experiments. Overall, our findings highlight that computational studies should explicitly account for $\mathrm{pH}$ and coverage effects under alkaline conditions for electrocatalytic oxidation reactions to reliably predict electrocatalytic behavior.

KEYWORDS: electro-oxidation, glycerol, electrocatalyst, electrolyte

\section{INTRODUCTION}

In this era of depleting fossil resources, the production of biofuels and specifically biodiesel has become immensely important. In biodiesel production via transesterification of triglycerides, glycerol emerges as a major byproduct, and accounts for approximately $10 \%$ of the total product mixture. ${ }^{1,2}$ The production of surplus glycerol has driven its market price down, ${ }^{3}$ and it has consequently been listed by the U.S. Department of Energy ${ }^{4}$ as one of the most important bioderived platform chemicals for synthesizing oxygenfunctionalized organic molecules. These molecules include organic acids, aldehydes, and ketones such as glyceric acid (GLA), glyceraldehyde (GLD), and dihydroxyacetone (DHA). Various approaches such as thermocatalytic oxidation, ${ }^{5-10}$ catalytic decomposition ${ }^{11-13}$ and hydrodeoxygenation, ${ }^{14,15}$ and electrocatalytic oxidation ${ }^{16-26}$ have been recently considered to utilize and upgrade the excess glycerol.

The thermocatalytic oxidation of glycerol has been extensively studied experimentally over numerous metal catalysts, ${ }^{6-10}$ but this approach has several shortcomings. For example, the intensive activation of oxidants, low conversion, poor selectivity, and high operating temperature and pressure are problematic. The catalytic decomposition ${ }^{11-13}$ of glycerol, on the other hand, is hindered by slow reaction kinetics due to high activation barriers, and the catalytic hydrodeoxygena- tion $^{14,15}$ is limited by high $\mathrm{H}_{2}$ pressures or flow rates. Both thermocatalytic and decomposition approaches produce mainly carbonaceous molecules with little to no oxygen content and fail to synthesize highly oxidized value-added chemicals. To improve selectivity toward the oxygen-rich products and to facilitate milder reaction conditions, the electrocatalytic oxidation of glycerol (EOG) has emerged as a highly competitive alternative. ${ }^{21,24,26}$ EOG can be efficiently operated at ambient reaction conditions eliminating the need for additional chemical oxidants such as oxygen or hydrogen peroxide. The electrocatalytic approach also allows finer control over activity and selectivity by modulating the applied electrode potential, electrolyte, and $\mathrm{pH}$. In addition, coupling anodic EOG with the hydrogen evolution reaction (HER) taking place at the cathode makes hydrogen production a valuable side reaction. ${ }^{25,27,28}$

Given its numerous advantages, EOG has been studied on various metal electrocatalysts, including $\mathrm{Au}{ }^{16,18,19,22,29,30}$

Received: August 20, 2021

Revised: November 26, 2021 
$\mathrm{Pd},{ }^{31,32} \mathrm{Pt},{ }^{19,23,25,29,33} \mathrm{Ni}^{34,35} \mathrm{Cu},{ }^{26}$ and $\mathrm{Rh}^{27}$ and their alloys such as $\mathrm{AuPd}^{36} \mathrm{AuPt}^{2} \mathrm{NiPt}^{37}$ and RuPt. ${ }^{37}$ Previous experiments $^{16,18,19,29}$ have shown that $\mathrm{Au}$ electrocatalysts exhibit promising EOG performance and high activity in alkaline media compared to other single metal electrodes. The extraordinary performance of $\mathrm{Au}$ in alkaline conditions has been explained by its resistance toward catalyst poisoning, ${ }^{18,38}$ that is, the formation of oxides or hydroxides at highly oxidizing potentials. For instance, Au's surface oxidation potential is $\sim 0.5 \mathrm{~V}$ higher than that of $\mathrm{Pt}^{39}$ indicating that, unlike $\mathrm{Pt}, \mathrm{Au}$ is not oxidized under the reaction conditions. $\mathrm{Au}$ has long been considered totally inactive toward EOG in acidic media due to the lack of proton acceptors such as $\mathrm{OH}^{-}$ions in solution. ${ }^{16,19,29}$ However, a recent joint experimental and computational study $^{22}$ demonstrated that $\mathrm{Au}$ retains some activity even under acidic conditions in $0.1 \mathrm{M} \mathrm{HClO}_{4}{ }^{22}$ while in $0.5 \mathrm{MH}_{2} \mathrm{SO}_{4}$, no activity was observed. ${ }^{16,19}$ The differences are likely related to the specific adsorption of $(\mathrm{H}) \mathrm{SO}_{4}{ }^{2-}$ which adsorbs on the surface even in dilute $(\mathrm{H}) \mathrm{SO}_{4}{ }^{2-}$ solutions. ${ }^{40,41}$ Perchlorate also adsorbs on the $\mathrm{Au}(111)$ surface although not as strongly as (hydrogen) sulfate ${ }^{42}$ which may explain the differences between the EOG activity in solutions containing $\mathrm{ClO}_{4}{ }^{-}$and $(\mathrm{H}) \mathrm{SO}_{4}{ }^{2-}$. Specifically, sulfates adsorb on the surface around $0.2 \mathrm{~V}$ vs $\mathrm{RHE}$ (henceforth referred to as $\mathrm{V}_{\mathrm{RHE}}$ ) in $1.0 \mathrm{MH}_{2} \mathrm{SO}_{4}$ reaching a total coverage of 0.2 monolayer (ML) at $1.05 \mathrm{~V}_{\mathrm{RHE}}{ }^{40}$ while perchlorate adsorbs under more oxidative conditions starting at $0.4 \mathrm{~V}_{\mathrm{RHE}}$ reaching a $0.15 \mathrm{ML}$ coverage at $1.05 \mathrm{~V}_{\mathrm{RHE}}$ in $0.1 \mathrm{M} \mathrm{HClO}_{4}{ }^{41}$

The promising results for Au-catalyzed EOG in alkaline media have led to substantial research efforts devoted to understand its activity and selectivity. $1,16,18,19,43-45$ Gaining molecular understanding of EOG, however, has been difficult due to the high functionality of glycerol (GLY) and the complex reaction network with a variety of possible product molecules. Furthermore, solution $\mathrm{pH}$ substantially affects the conversion, activity, selectivity, and yield. ${ }^{5,19,21}$ In highly alkaline conditions, GLY oxidation is considered to take place via the primary hydroxyl group producing glyceraldehyde (GLD), which is very unstable under these conditions and quickly oxidizes to the first primary product, glyceric acid (GLA). ${ }^{18,19}$ Further oxidation products include, e.g., glycolic acid and formic acid. ${ }^{19}$ Under neutral and acidic conditions, $\mathrm{Au}$ electrocatalysts mainly produce dihydroxyacetone (DHA) via the oxidation of a secondary $\mathrm{C}$ group in $\mathrm{GLY}^{22}$ but minor amounts of GLD have also been observed under neutral conditions using a $\mathrm{Na}_{2} \mathrm{SO}_{4}$ electrolyte. ${ }^{19}$ Further oxidation of DHA under acidic conditions may lead to various products, such as, e.g., hydroxypyruvic acid and mesoxalic acid. ${ }^{24}$ Production of DHA-derived species, however, depends on the electrochemical conditions.

Previous alcohol electro-oxidation experiments indicate that the catalytic performance of $\mathrm{Au}$ in an alkaline environment results from the formation of surface-adsorbed hydroxide species (referred to as $\mathrm{Au}(\mathrm{OH})_{\text {ads }}$ ). ${ }^{16,39,46,47} \mathrm{Au}(\mathrm{OH})_{\text {ads }}$ species are known to directly participate in various alcohol oxidation reactions by lowering the $\mathrm{C}-\mathrm{H}$ and $\mathrm{O}-\mathrm{H}$ bond dissociation barriers. ${ }^{4-50}$ The precise role of $\mathrm{Au}(\mathrm{OH})_{\text {ads }}$ on the reaction mechanism, thermodynamics, and kinetics is currently well understood for the oxidation of simple alcohols, such as methanol and ethanol. ${ }^{49,50}$ The effects of $\mathrm{pH}$ in more complex electro-oxidation reactions of multifunctional alcohols, like GLY, however, are less well understood. For instance, the role of aqueous $\mathrm{OH}^{-}$ion or adsorbed $\mathrm{OH}$ on the EOG mechanism or kinetics under different electrochemical conditions has not been explored in atomic detail. The exact EOG mechanism remains controversial. Issues such as whether $\mathrm{Au}(\mathrm{OH})_{\text {ads }}$ catalyzes the dissociation of a $\mathrm{C}-\mathrm{H}$ bond ${ }^{51,52}$ or an $\mathrm{O}-\mathrm{H}$ bond, ${ }^{2,18,19,24}$ and whether primary or secondary $\mathrm{O}-\mathrm{H} /$ $\mathrm{C}-\mathrm{H}$ bonds are more reactive on the bare Au surface have remained unresolved. ${ }^{22,53}$ Experiments have shown that, under alkaline conditions close to or above the glycerol $\mathrm{p} K_{\mathrm{a}}(14.15)$, the dissociation of the primary $\mathrm{O}-\mathrm{H}$ bond to glycerolate (GLD1) and even the formation of GLD may be driven by aqueous $\mathrm{OH}^{-}$ions. ${ }^{18,54}$ It remains unclear, however, whether the aqueous hydroxide or $\mathrm{Au}(\mathrm{OH})_{\text {ads }}$ is responsible for catalyzing the first $\mathrm{O}-\mathrm{H}$ dissociation under less alkaline conditions where the concentration of GLD1 decreases exponentially. Regardless of the mechanism that forms GLD1, oxidation to GLA or further requires an electrocatalyst and either glycerolate or glycerol must adsorb onto the surface. ${ }^{18,54}$ In addition, chemical steps, such as the keto-enol tautomerism between DHA and GLD which has been identified for thermochemical glycerol oxidation, ${ }^{55,56}$ may contribute to EOG under different $\mathrm{pH}$ conditions.

Though the thermodynamic origin of an electrocatalyst's EOG activity and selectivity as a function of the $\mathrm{pH}$ and the electrode potential is partially understood from computations and experiments, the elementary kinetics has not been addressed even under acidic EOG conditions. ${ }^{22}$ Instead, the kinetics have been analyzed computationally only for thermocatalytic glycerol decomposition on close-packed transition metal surfaces such as $\operatorname{Pt}(111),{ }^{11,57} \operatorname{Pd}(111),{ }^{13}$ $\mathrm{Rh}(111),{ }^{13} \mathrm{Cu}(111),{ }^{13}$ and $\mathrm{Ni}(111) .{ }^{13}$ These results, however, are not directly transferable to EOG as the $\mathrm{pH}$, electrode potential, and solvent effects have been omitted. Furthermore, experimental studies show that many thermocatalytic materials undergo surface oxidation and subsequent deactivation at relevant electrode potentials ${ }^{19,39}$ but such information for EOG active catalysts is still scarce.

In this work, we performed density functional theory (DFT) calculations to elucidate the initial EOG reaction mechanism on $\mathrm{Au}$ under different electrochemical reaction conditions and to understand how the activity and selectivity are modulated by the $\mathrm{pH}$ and electrode potentials. Specifically, the influence of the $\mathrm{pH}$ and potential on the EOG thermodynamics and kinetics was carefully analyzed. Pourbaix diagrams computed with the grand canonical ensemble DFT (GCE-DFT) are used to estimate the coverage of $\mathrm{OH}$ species on $\mathrm{Au}$ in oxidative environments as a function of $\mathrm{pH}$ and potential. The Pourbaix analysis is followed by a computational investigation of elementary reaction steps from GLY to dihydroxyacetone, glyceraldehyde, and glyceric acid at different $\mathrm{pH}$ conditions. Our findings show that the presence of $\mathrm{Au}(\mathrm{OH})_{\text {ads }}$ species and keto-enol tautomerism are critical in explaining the experimentally observed $\mathrm{pH}$-dependent EOG activity and selectivity on Au. In alkaline conditions, high activity and selectivity toward GLA stem from adsorbed $\mathrm{OH}$ whereas the absence of $\mathrm{Au}(\mathrm{OH})_{\text {ads }}$ leads to slow kinetics and DHA as the main product.

\section{COMPUTATIONAL DETAILS}

All density functional theory (DFT) $)^{58,59}$ calculations were performed with the GPAW 1.5.2 software. $^{60-62}$ The projectoraugmented wave (PAW) ${ }^{63}$ formalism was employed to treat the frozen core electrons. The Kohn-Sham equations were solved using a real-space grid method with a grid spacing of 
$0.18 \AA$, which has been demonstrated to yield converged energies for alcohols and oxides on $\mathrm{Au}^{64}$ The exchange and correlation effects were described using the $\mathrm{PBE}^{65,66}$ functional with the Tkatchenko and Scheffler (TS09) ${ }^{67}$ dispersion correction. The solvent was accounted for by using a continuum solvent model ${ }^{68}$ for water as implemented in GPAW. For oxygen and hydrogen, standard cavity radii ${ }^{68}$ were used but a larger radius of $2.0 \AA$ was used for Au based on our previous results. ${ }^{69}$ The details of the grand-canonical ensemble (GCE)-DFT calculations can be found in the Supporting Information.

The Au lattice constant was calculated to be $4.142 \AA$, which agrees well with the experimental value $\left(4.065 \AA^{70}\right)$. An $\mathrm{Au}(111)$ surface was selected to model the electrode surface because it is the most stable and abundant Au surface. ${ }^{71}$ It also exhibits the highest EOG activity among the simple gold single crystal surfaces. ${ }^{54}$ While $\mathrm{Au}(111)$ can reconstruct under electrochemical conditions due to the electrode potential and the electrolyte species, ${ }^{40}$ this is beyond the focus of the present study. The $\mathrm{Au}(111)$ surface consists of a four-layer periodic 3 $\times 4$ orthogonal unit cell. The coordinates of bottom two layers were fixed at their ideal bulk positions, while the top two layers were allowed to relax. The surface slabs were separated by a continuum solvent of $10 \AA$ on both sides of the slab and a $4 \times 4$ $\times 1$ k-point mesh was applied. Test calculations with $(3 \times 2 \times$ $1,3 \times 3 \times 1$ and $4 \times 3 \times 1)$ k-point samplings showed that adsorption energies of GLY and $\mathrm{OH}$ were underestimated by 0.05-0.09 eV, while $(5 \times 4 \times 1$ and $5 \times 5 \times 1)$ k-point samplings predicted the energies within $0.01 \mathrm{eV}$ compared to a $4 \times 4 \times 1$ k-point sampling. The aqueous-phase species were treated in nonperiodic unit cells with $20 \AA$ of implicit solvent in each direction. The geometry optimization was done using the BFGS method until the maximum residual force was below $0.05 \mathrm{eV} \AA^{-1}$. First-order saddle points (transition states) on the potential energy surface (PES) were located using the climbing image nudged elastic band (CI-NEB) method, ${ }^{72-74}$ and the forces were converged below $0.05 \mathrm{eV} \AA^{-1}$ except for the transition state of $\mathrm{R} 9$ on a $1 / 3 \mathrm{ML}$ surface where the convergence criteria was relaxed to $0.15 \mathrm{eV}^{-1}$. The additional degrees of freedom introduced by the increased number of $\mathrm{OH}$ on the surface made convergence below $0.05 \mathrm{eV} / \AA$ tedious. Intermediate images were created using the image-dependent pair potential (IDPP) interpolation scheme. ${ }^{75}$

A vibrational analysis was carried out for all optimized minimum and transition state structures. The transition state structures were confirmed to have a single imaginary frequency. All free energies were calculated at NTP conditions and aqueous-phase free energies were obtained using the idealgas approximation. The free energies of surface-bound adsorbates were computed using hindered $2 \mathrm{D}$ rigid-rotor/ translator approximation to account for the adsorbate free energies. ${ }^{76,77}$ The rotational and translational barriers were taken to be 0.05 and $0.1 \mathrm{eV}$, respectively, which are typical values for adsorbed organic molecules. ${ }^{76}$ Given the negligible $p \mathrm{~V}$ term for adsorbed species, the Gibbs free energies are comparable to Helmholtz free energies (see the Supporting Information for further details).

Computation of Adsorption, Activation, and Electrochemical Free Energies. The adsorption free energies $\left(\Delta G_{\text {ads }}\right)$ of glycerol and its derivatives were computed as follows:

$$
\Delta G_{\mathrm{ads}}=G\left(\mathrm{~A}^{*}\right)-G(\mathrm{~A})-G(*)
$$

where $G\left(\mathrm{~A}^{*}\right), G(\mathrm{~A})$, and $G(*)$ represent the free energies of the surface-bound species, the isolated aqueous-phase species, and the bare surface, respectively.

The activation free energies $\left(\Delta G_{\text {act }}\right)$ for an elementary reaction step were determined as

$$
\Delta G_{\text {act }}=G^{\mathrm{TS}}-G^{\mathrm{RE}}
$$

where $G^{\mathrm{TS}}$ and $G^{\mathrm{RE}}$ are the free energies of optimized transition state and reactant structures, respectively. For some highly exergonic $\mathrm{Au}(\mathrm{OH})_{\mathrm{ads}}$-catalyzed dehydrogenation reactions, transition states were impossible to locate as the reactants immediately converted to the corresponding product during structure optimization. We ensured that this behavior does not result from our computational setup but genuine features of the studied system as shown in the Supporting Information.

The EOG reaction free energies were computed using the computational hydrogen electrode (CHE) model, ${ }^{78}$ which treats the electrochemical potentials of proton and electron at equilibrium with $(1 / 2) \mathrm{H}_{2}$ under standard conditions.

$$
\tilde{\mu}_{\mathrm{H}^{+}}+\tilde{\mu}_{\mathrm{e}^{-}}=1 / 2 \mu_{\mathrm{H}_{2}}
$$

We mainly used the reversible hydrogen electrode (RHE) scale, which can be obtained from standard hydrogen electrode $(\mathrm{SHE})$ as $U_{\mathrm{RHE}}=U_{\mathrm{SHE}}+n k_{\mathrm{B}} T \ln 10 \times \mathrm{pH}$. On the RHE scale, the potential-dependent free energies for the oxidation steps $\left(\Delta G\left(U_{\mathrm{RHE}}\right)\right)$ within the CHE approximation are obtained as

$$
\Delta G\left(U_{\mathrm{RHE}}\right)=\Delta G(U=0)-n e U_{\mathrm{RHE}}
$$

where $n$ is the number of electrons transferred and $e$ is elementary charge.

The EOG thermodynamics are discussed in terms of the standard equilibrium potential $\left(U_{\mathrm{eq}}^{0}\right)$ and the surface equilibrium potential ( $\left.U_{\mathrm{eq}}^{\text {surf }}\right)$ which use the solution and surface species as references, respectively. The $U_{\text {eq }}^{0}$ and $U_{\text {eq }}^{\text {surf }}$ values correspond to $\mathrm{CHE}$-derived equilibrium potentials, where reactant and product species are equally stable. We also use the limiting potential $\left(U_{\mathrm{L}}\right)$ to determine which applied electrode potential makes all elementary steps spontaneous or thermoneutral. These potentials are defined as

$$
\begin{aligned}
& U_{\text {eq }}^{0}(\mathrm{RHE})=\left[\sum_{i} \Delta G(\mathrm{aq})_{i}(U=0 \text { vs RHE })\right] / n_{e, \text { tot }} \\
& U_{\text {eq }}^{\text {surf }}(\mathrm{RHE})=\left[\sum_{i} \Delta G_{i}^{*}(U=0 \text { vs RHE })\right] / n_{e, \text { tot }} \\
& U_{\mathrm{L}}=\max \left\{\Delta G_{i}(U=0 \text { vs RHE })\right\}
\end{aligned}
$$

where index $i$ denotes an electrochemical reaction step and * refers to an adsorbed species.

While the potential-dependent kinetics was not explicitly addressed, we confirmed that the Fermi levels are reasonably close to the experimentally relevant potential range of $0.2-1.1$ $\mathrm{V}_{\mathrm{RHE}}$. The Fermi levels correspond to absolute electrode potentials $^{69}$ and can be converted to the RHE scale through $U(\mathrm{SHE})=-e\left(E_{\mathrm{F}}+4.44 \mathrm{eV}\right)$ using the implicit solvent model. The Fermi levels (electrode potentials vs RHE) are $-4.8 \mathrm{eV}$ $(0.2 \mathrm{~V}$ at $\mathrm{pH}=0$ and 0.96 at $\mathrm{pH}=13),-4.8 \mathrm{eV}(0.2 \mathrm{~V})$, and $-4.9 \mathrm{eV}(0.3 \mathrm{~V}$ at $\mathrm{pH}=0$ and 1.06 at $\mathrm{pH}=13)$ for GLY adsorption, neutral/acidic NEB calculations, and alkaline NEB calculations, respectively. At other potentials, the barriers can be estimated using a Butler-Volmer-like equation, 
$\Delta \Delta G^{\dagger}(\Delta U) \approx 0.5 \times \Delta U$, derived from the general grand canonical rate theory. ${ }^{79}$ During NEB calculations, the changes in the potential are less than $\pm 0.05 \mathrm{~V}$.

Surface Pourbaix Diagrams. A surface Pourbaix diagram represents the thermodynamic stability of different phases as a function of the electrode potential and $\mathrm{pH}$. Here, we constructed surface Pourbaix diagrams in order to understand the precise role and abundance of surface-bound $\mathrm{OH}$ species in alkaline EOG. ${ }^{80}$ The oxidation of liquid water is considered to occur through the following mechanism:

$$
\mathrm{H}_{2} \mathrm{O}(\mathrm{l})+* \rightleftharpoons \mathrm{OH}^{*}+1 / 2 \mathrm{H}_{2}
$$

To model water oxidation and $\mathrm{OH}$ coverage as a function of the electrode potential and $\mathrm{pH}$, we carried out GCE-DFT calculations, ${ }^{69}$ detailed in the Supporting Information. The computational procedure was as follows: various $\mathrm{OH}$ coverages for a range of constant potentials were simulated using the SJM method $^{81}$ to obtain surface grand free energies as a function of the electrode potential on the SHE scale. These values were then converted to RHE scale and the treatment of Duan and Henkelman $^{82}$ was followed to explicitly address the $\mathrm{pH}$ effects. As derived in the Supporting Information, the $\mathrm{OH}$ adsorption grand free energies on the RHE scale are computed using

$$
\begin{aligned}
\Delta G_{\mathrm{ads}}\left(U_{\mathrm{RHE}}\right)= & n \times\left[1 / 2 \mu_{\mathrm{H}_{2}}-U_{\mathrm{RHE}}\right]+\mu_{\mathrm{Au}(\mathrm{OH})_{n}} \\
& -\left[n \mu_{\mathrm{H}_{2} \mathrm{O}}+\mu_{\mathrm{Au}}(\mathrm{RHE})\right]
\end{aligned}
$$

where $\mu$ is the chemical potential of the given species. To obtain quantitatively accurate predictions for the $\mathrm{OH}$ adsorption energies, it is necessary to consider the deficiencies of the implicit solvent model applied. To that end, we also tested the effect of explicit solvent interactions by adding a correction of $0.53 \mathrm{eV}$ for each adsorbed $\mathrm{OH}$. This value was obtained by comparing $\mathrm{OH}$ adsorption energies calculated with an implicit solvent model and ab initio molecular dynamic simulations of an explicitly solvated $\mathrm{Au}(111)$ interface. ${ }^{83}$ The solvent correction, however, overstabilizes the $\mathrm{OH}$ adsorption. For example, if the stabilization by explicit solvent interactions is accounted for, full $\mathrm{OH}$ coverage at $\mathrm{pH}=13$ is predicted to take place at $0.76 \mathrm{~V}_{\mathrm{RHE}}$ (see Figure S2) which is much lower than seen experimentally ${ }^{54}$ (see Figure S2). It is possible that corrections for explicit solvent interactions depend on the surface coverage, but determining this relationship is outside the scope of the work presented here. We also considered the impact of the DFT functional on the $\mathrm{OH}$ adsorption energies and potentials as shown in the Supporting Information. Finally, we assessed the role of the adsorbed glycerol on the $\mathrm{OH}$ adsorption energy and coverage. Given the uncertainties related to the explicit solvent correction and the functional used, only the uncorrected values obtained directly from DFT are presented in the main text.

The electrosorption of species other than $\mathrm{OH}$ as a function of the potential was neglected. This is justified through the recently developed decoupled-CHE model, ${ }^{84}$ which uses the electrosorption valency $(\gamma)$ and the amount of charge transfer $\left(\delta_{e}\right)$ from the surface to the adsorbate to model electrosorption free energies as $\Delta G(U)_{\text {ads }} \propto \Delta G_{\text {ads }}(U=0)+\gamma \delta_{e}$. Our calculations show that $\delta_{e} \approx 0$ for the adsorption of the EOG products (see Supporting Information) and, therefore, their adsorption energies are expected to display only weak dependence on the electrode potential.

\section{RESULTS}

Glycerol Adsorption on Au(111). GLY exhibits various possible conformers; therefore, we considered the three most stable liquid-phase isomers identified in a previous extensive conformational analysis. ${ }^{85}$ In agreement with the previous study, ${ }^{85}$ we found conformer iii was the most stable (see Figure S3 and Table S2). Figure 1 displays the most stable GLY

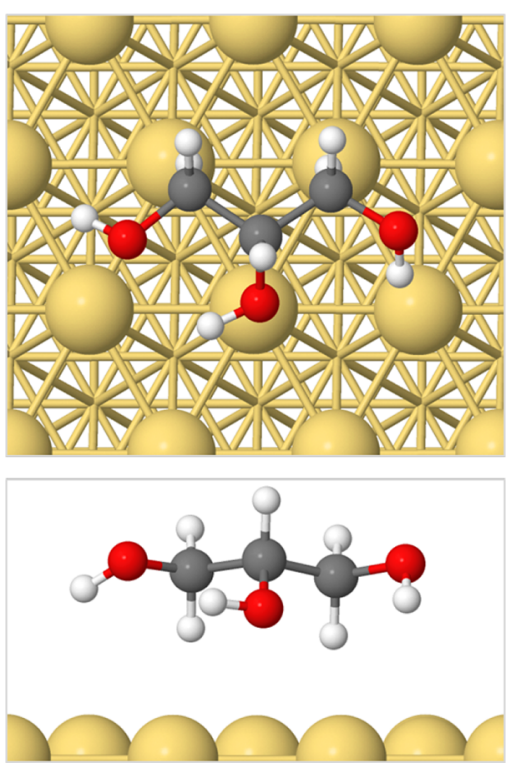

Figure 1. Most stable adsorption configuration of GLY over the $\mathrm{Au}(111)$ surface.

adsorption geometry, while all other adsorption structures and corresponding adsorption energies are given in Figure S4 and Table S3, respectively. The adsorption energy of the most stable conformer in water was calculated to be $-0.69 \mathrm{eV}$ $\left(\Delta G_{\mathrm{ads}}=-0.29 \mathrm{eV}\right)$, which is $0.09 \mathrm{eV}$ more exergonic than the value computed in the gas phase. ${ }^{22,86}$ As shown in Table S3, van der Waals interactions are needed to make the GLY adsorption exothermic as they stabilize GLY adsorption by $\sim 0.7 \mathrm{eV}$ and are therefore used throughout the present work. The implicit solvent also greatly stabilizes GLY adsorption, but this effect may partially be overestimated by the deficiencies inherent to dielectric continuum models. ${ }^{87}$ The Bader charge analysis shows only a minor charge transfer (0.08 e) upon GLY adsorption on $\mathrm{Au}$ indicating that the electrode potential has only a small influence on GLY adsorption energy on Au.

Surface Pourbaix Diagrams. To address the $\mathrm{pH}$ effects in EOG, we start with surface Pourbaix diagrams for $\mathrm{OH}$ adsorption on $\mathrm{Au}(111)$ at $298 \mathrm{~K}$. Figure 2 displays adsorption energies as a function of the electrode potential and $\mathrm{pH}$ at different coverages. The $\mathrm{OH}$ adsorption potentials as a function of $\mathrm{pH}$ are provided in Table S6. At 1/12 ML coverage, $\mathrm{OH}$ resides at a $f c c$ hollow site but the adsorbed $\mathrm{OH}$ favors other sites with increasing coverage. For example, at 1/6 and $1 / 4 \mathrm{ML}$, bridge sites are preferred whereas top sites are occupied at $1 / 3,1 / 2$, and $1 \mathrm{ML}$.

At $\mathrm{pH}=0, \mathrm{OH}$ adsorption is thermodynamically unfavorable and the gold surface remains clean up to 1.35 $\mathrm{V}_{\mathrm{RHE}}$, at which point low $\mathrm{OH}$ coverage structures (1/12 and 1/ $6 \mathrm{ML}$ ) become stable. As the $\mathrm{pH}$ increases, 1/12 ML of $\mathrm{OH}$ becomes increasingly unstable, whereas the adsorption energy for 1/6 ML coverage is nearly independent of $\mathrm{pH}$. These 

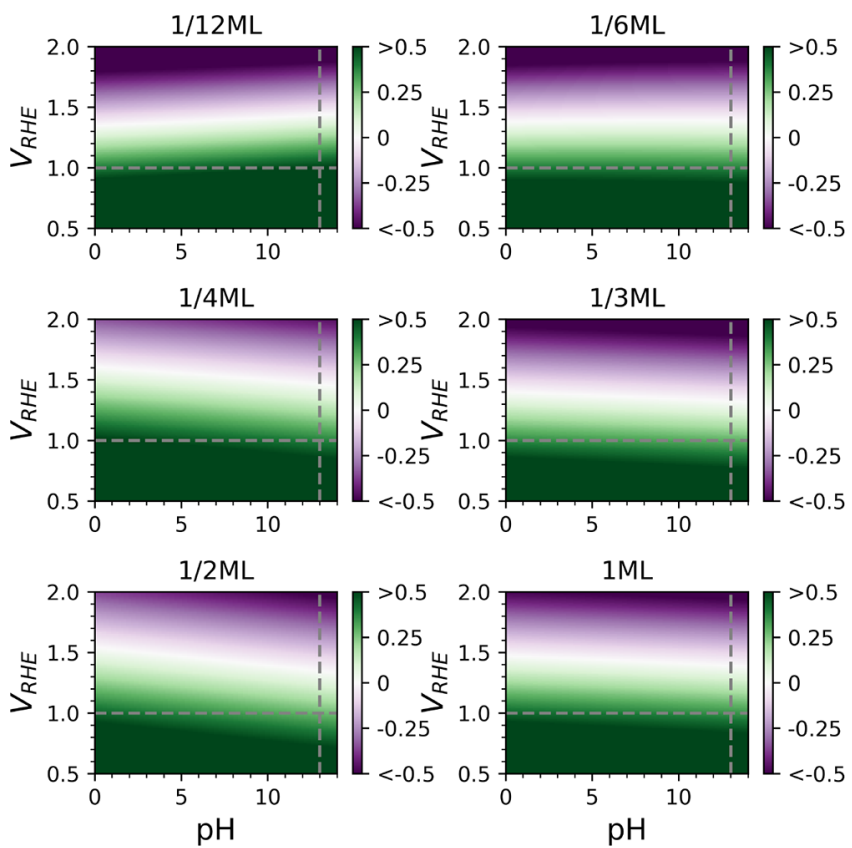

Figure 2. $\mathrm{OH}$ adsorption energies as a function of $\mathrm{pH}$ on the RHE scale with an implicit solvent model. The dotted lines depict typical glycerol onset potentials at alkaline reaction conditions. The units for the scale are in $\mathrm{eV}$.

results agree with previous experimental ${ }^{38,40,88}$ and computational studies ${ }^{38,88}$ reporting that $\mathrm{OH}$ adsorption at $\mathrm{pH}=0$ takes place around 1.05-1.5 $\mathrm{V}_{\mathrm{RHE}}$. While our $\mathrm{OH}$ adsorption potentials are slightly higher than those reported previously, the differences can be ascribed to the errors in $\mathrm{OH}$ adsorption on $\mathrm{Au}$, which are around $0.15 \mathrm{eV}$ and result from the use of the PBE functional ${ }^{89}$ or the flavor of the dispersion correction ${ }^{90}$ as discussed in the Supporting Information and shown in Figure S2 and Table S6. If the error due to the functional is accounted for, then $\mathrm{OH}$ adsorption under acidic condition becomes possible at $1.20 \mathrm{~V}_{\mathrm{RHE}}$. In addition, experimental measurements are often performed in solutions containing $\mathrm{SO}_{4}{ }^{2-}$ or $\mathrm{ClO}_{4}{ }^{-}$ species which also adsorb on gold surfaces and directly influence the $\mathrm{OH}$ adsorption/desorption potential under acidic and, to a lesser extent, neutral conditions by blocking possible $\mathrm{OH}$ adsorption sites. ${ }^{40,41,88}$

$\mathrm{OH}$ adsorption at coverages higher than 1/4 ML becomes thermodynamically more favorable with increasing $\mathrm{pH}$. This type of $\mathrm{pH}$ dependency, known as a non-Nernstian shift, results from shifts in the zero charge potential of the interface as a function of coverage and the surface dipole. ${ }^{91}$ Figure 2 and Table S6 show that the $1 / 3 \mathrm{ML} \mathrm{OH}$ structure is the most stable configuration under typical alkaline conditions of $\mathrm{pH}=$ 13 and has a adsorption potential of $1.29 \mathrm{~V}_{\mathrm{RHE}}$. The $1 / 2 \mathrm{ML}$ $\mathrm{OH}$ coverage at $\mathrm{pH}=13$ is almost equally stable and becomes thermodynamically stable at $1.34 \mathrm{~V}_{\mathrm{RHE}}$. If errors in the adsorption energies caused by the DFT functional are accounted for, both $1 / 3 \mathrm{ML}$ and $1 / 2 \mathrm{ML}$ coverages become stable around $1.15 \mathrm{~V}_{\mathrm{RHE}}$ as shown in Figure S2 and Table S6. The results in Figures 2 and S2 and Table S2 are again in good agreement with the experimental results ${ }^{92,93}$ under alkaline conditions showing that $\mathrm{OH}$ adsorption starts around $0.6 \mathrm{~V}_{\mathrm{RHE}}$ and reaches a maximum coverage of $0.4-0.5 \mathrm{ML}$ around 1.3 $\mathrm{V}_{\mathrm{RHE}}{ }^{54}$ While our predictions on stable $\mathrm{OH}$ coverages are consistent with experiments, the adsorption potentials are again slightly higher than those observed experimentally and this is attributed to DFT errors, surface reconstructions ${ }^{93}$ as well as the presence of ions in experiments.

Finally, we addressed the effect of glycerol adsorption on $\mathrm{OH}$ adsorption energies. A GLY coverage of 1/12 $\mathrm{ML}$ enhances $\mathrm{OH}$ adsorption by $\sim 0.15 \mathrm{e}$ and $\sim 0.05 \mathrm{eV}$ at $1 / 12$ and 1/6 ML OH coverages, respectively. The glycerol-OH Pourbaix diagram (see Figure S15) shows the coadsorbed $\mathrm{OH}$ GLY becoming stable around $0.7 \mathrm{~V}_{\mathrm{RHE}}$. Glycerol coadsorption is therefore expected to facilitate $\mathrm{OH}$ adsorption allowing the oxidation reaction to begin at slightly lower potentials than predicted based on $\mathrm{OH}$ adsorption alone. This suggestion is supported $^{93}$ by the slightly shifted oxidation peak of simpler alcohols.

The onset potential of EOG on $\mathrm{Au}$ at $\mathrm{pH}=13$ is $\sim 1.0 \mathrm{~V}_{\mathrm{RHE}}$, and all the activity is lost after $\sim 1.4 \mathrm{~V}_{\mathrm{RHE}} \cdot{ }^{19}$ We have not explored the surface oxide formation because it starts at 1.54 $\mathrm{V}_{\mathrm{RHE}}$ according to an extensive experimental and computational study. ${ }^{38}$ These observations indicate that alkaline EOG activity on $\mathrm{Au}$ is closely related to the formation of surface hydroxides in the presence of GLY, which may take place at experimentally relevant EOG potentials of $0.8-1.4 \mathrm{~V}_{\mathrm{RHE}}{ }^{54}$

Overall, the computed Pourbaix diagrams and $\mathrm{OH}$ adsorption energies show that $\mathrm{OH}$ adsorption exhibits a nonNernstian shift on the RHE scale. Under acidic conditions, only low $\mathrm{OH}$ surface coverages are likely to be observed in the potential region relevant for EOG. Under alkaline conditions a moderate $\mathrm{OH}$ coverage between $1 / 3$ and $1 / 2 \mathrm{ML}$ is predicted to exist under EOG potentials. Glycerol stabilizes $\mathrm{OH}$ adsorption indicating that both GLY and $\mathrm{OH}$ are simultaneously present on the surface at the experimentally relevant EOG conditions. Computational models for Au-catalyzed alkaline EOG should therefore explicitly account for the influence of the $\mathrm{OH}$ coverage.

Electrocatalytic Oxidation of Glycerol under Neutral and Acidic Conditions. We have considered four competing pathways producing either dihydroxyacetone (DHA) or glyceraldehyde (GLD). DHA is the major EOG product on $\mathrm{Au}$ under acidic or neutral conditions but has low yields, ${ }^{22}$ whereas GLD formation has only been observed under neutral conditions and at high potential. ${ }^{19}$ Figure 3 summarizes the elementary mechanism and energetics of the reaction pathways considered for EOG on $\mathrm{Au}(111)$ : RS1 and RS2 lead to DHA while RS3 and RS4 form GLD. RS1 starts with the oxidation of the secondary $\mathrm{OH}$ group followed by the oxidation of the secondary $\mathrm{CH}$ group to produce DHA, while along the RS2 reaction pathway, the elementary steps take place in the reverse order. Similarly, GLD production goes through a two-step oxidation process but this time through the primary $\mathrm{CH}_{2} \mathrm{OH}$ fragment via pathways RS3 and RS4. According to our Pourbaix diagrams, the $\mathrm{Au}(111)$ surface is either free of $\mathrm{OH}$ species or has a low $\mathrm{OH}$ coverage at relevant electrochemical potentials under acidic and neutral reaction conditions. We model the acidic and neutral conditions on the bare Au surface but acknowledge that at highly oxidative potentials $\mathrm{OH}$ might be present on the surface. We also note that experimental studies under acidic or neutral conditions are performed in the presence of specifically adsorbing anions but these are not considered in the present study.

Acidic and Neutral EOG Thermodynamics. For the thermodynamic analysis of EOG, we carried out a careful screening of intermediate and product adsorption structures by considering various configurations and active sites. Stable adsorption geometries and energies are presented in Figure S5 


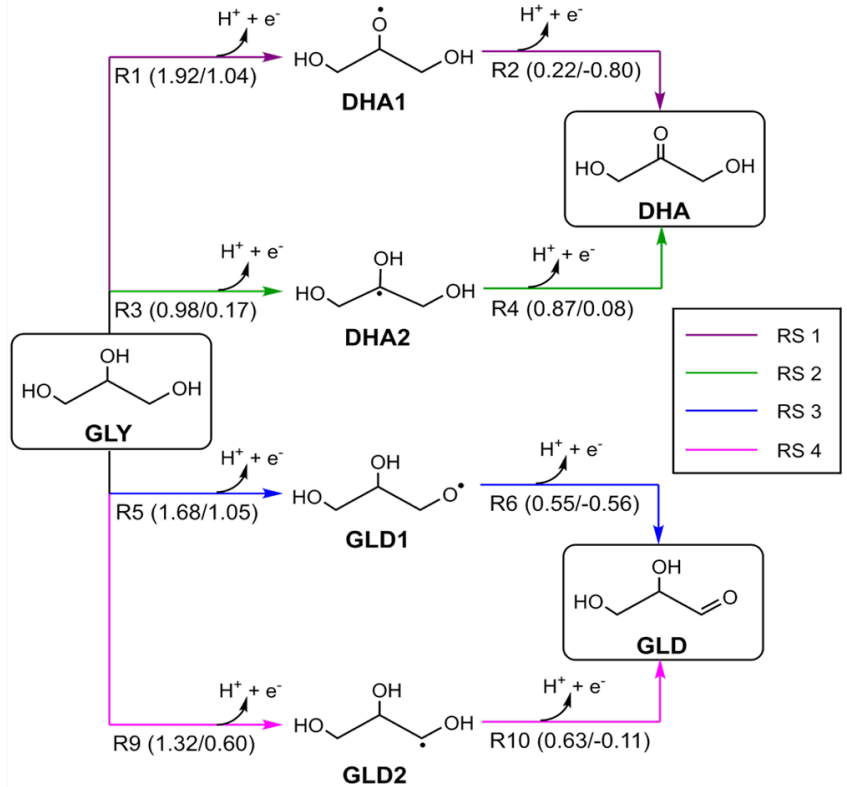

Figure 3. Reaction mechanism of glycerol (GLY) oxidation to dihydroxyacetone (DHA) and glyceraldehyde (GLD) in acidic/ neutral environment and NTP ensemble conditions. Rn beneath arrows denotes a reaction number along the RS1-RS4 pathways, and the quantities provided in the parentheses are activation free energy/ reaction free energy in $\mathrm{eV}$.

and Table S4, respectively. Figure 3 summarizes the main results and a detailed description of the thermodynamic free energy surfaces at $298 \mathrm{~K}$ along the RS1-RS4 pathways can be found in Figure S5. After GLY adsorption onto the electrode, the first bond breaking steps along all the pathways are endergonic. Figure 3 shows that the oxidation of secondary and primary C groups (RS2 and RS4) is thermodynamically more favorable than the oxidation of secondary and primary $\mathrm{OH}$ groups ( $\mathrm{RS} 1$ and $\mathrm{RS} 3$ ). Furthermore, $\mathrm{H}$ elimination from the secondary carbon $\left(\mathrm{GLY}^{*} \rightleftharpoons \mathrm{DHA} 2^{*}\right.$ ) is more favorable than the abstraction of the primary $\mathrm{H}\left(\mathrm{GLY}^{*} \rightleftharpoons \mathrm{GLD} 2^{*}\right)$. Along RS2, the second elementary step is a $\mathrm{H}$ elimination from the secondary $\mathrm{OH}$ group leading to DHA formation followed by its desorption. Overall, the thermodynamic analysis indicates that on $\mathrm{Au}, \mathrm{EOG}$ produces mainly $\mathrm{DHA}$ at acidic and neutral $\mathrm{pH}$ conditions via $\mathrm{RS} 2$ pathway in agreement with a previous computational study. ${ }^{22}$

Figure 4 presents potential-dependent thermodynamics for the favored RS2 and RS4 pathways at $\mathrm{pH}=0$ and at different potentials corresponding to the computed $U=0 \mathrm{~V}, U_{\text {eq }}^{0}, U_{\text {eq }}^{\text {surf }}$, and $U_{\mathrm{L}}$ values. The last thermodynamic steps, $\mathrm{DHA}^{*} \rightleftharpoons$ $\operatorname{DHA}(\mathrm{aq})$ and $\mathrm{GLD}^{*} \rightleftharpoons \mathrm{GLD}(\mathrm{aq})$, removing the products from $\mathrm{Au}(111)$ into the liquid phase, are chemical steps and therefore independent of the applied potential. Figure 4 clearly shows that DHA production is thermodynamically more facile with a limiting potential of $0.17 \mathrm{~V}_{\mathrm{RHE}}$ than GLD formation for which the limiting potential is $0.60 \mathrm{~V}_{\mathrm{RHE}}$. These findings are in line with previously reported values of 0.39 (DHA) and 0.60 (GLD) $\mathrm{V}_{\mathrm{RHE}}$ computed in vacuum and at $\mathrm{pH}=0$, where the RHE and SHE scales are identical. ${ }^{22}$ In the $\mathrm{pH}$ range $1-4$, the limiting potential for GLY to DHA oxidation varies from 0.23 $\mathrm{V}_{\mathrm{RHE}}$ to $0.41 \mathrm{~V}_{\mathrm{RHE}}$ and for GLY to GLD transformation from $0.66 \mathrm{~V}_{\mathrm{RHE}}$ to $0.84 \mathrm{~V}_{\mathrm{RHE}}$. This further supports our finding that DHA formation is thermodynamically favored via the RS2 pathway in acidic and neutral media.

Acidic and Neutral EOG Kinetics. The acidic and neutral EOG kinetics toward DHA and GLD along four competing pathways was explored. Figure 3 provides the computed activation barriers for each elementary step, while the complete potential free energy surfaces and transition state structures are provided in Figures S6 and S9, respectively. We find that, regardless of the product molecule, GLY deprotonation occurs via the $\mathrm{C}-\mathrm{H}$ bond cleavage. The deprotonation of the secondary C, leading to DHA2, has a barrier of $0.98 \mathrm{eV}$, which is $\sim 0.3 \mathrm{eV}$ lower than the barrier for the deprotonation of the primary $\mathrm{C}$ leading to GLD2. The subsequent deprotonation
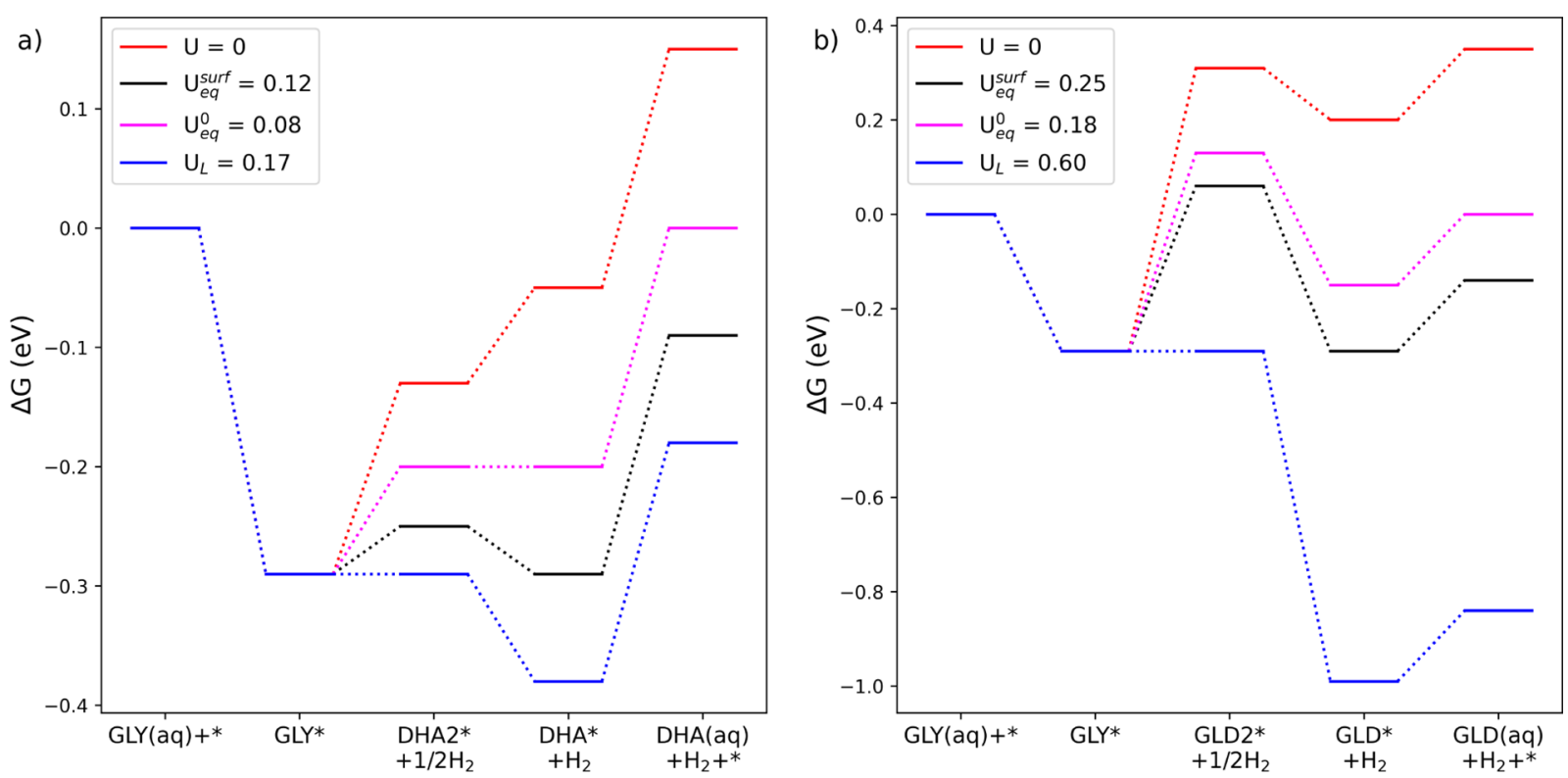

Figure 4. Potential-dependent $(\mathrm{pH}=0)$ oxidation thermodynamics for GLY conversion to (a) dihydroxyacetone (DHA) and (b) glyceraldehyde (GLD) on the $\mathrm{Au}(111)$ surface. Free energies are shown for zero potential, the surface equilibrium potential, $U_{\text {eq }}^{\text {surf }}$, the standard equilibrium potential, $U_{\mathrm{eq}}^{0}$ and the limiting potential, $U_{\mathrm{L}}$, in $\mathrm{V}_{\mathrm{RHE}}$, respectively. 


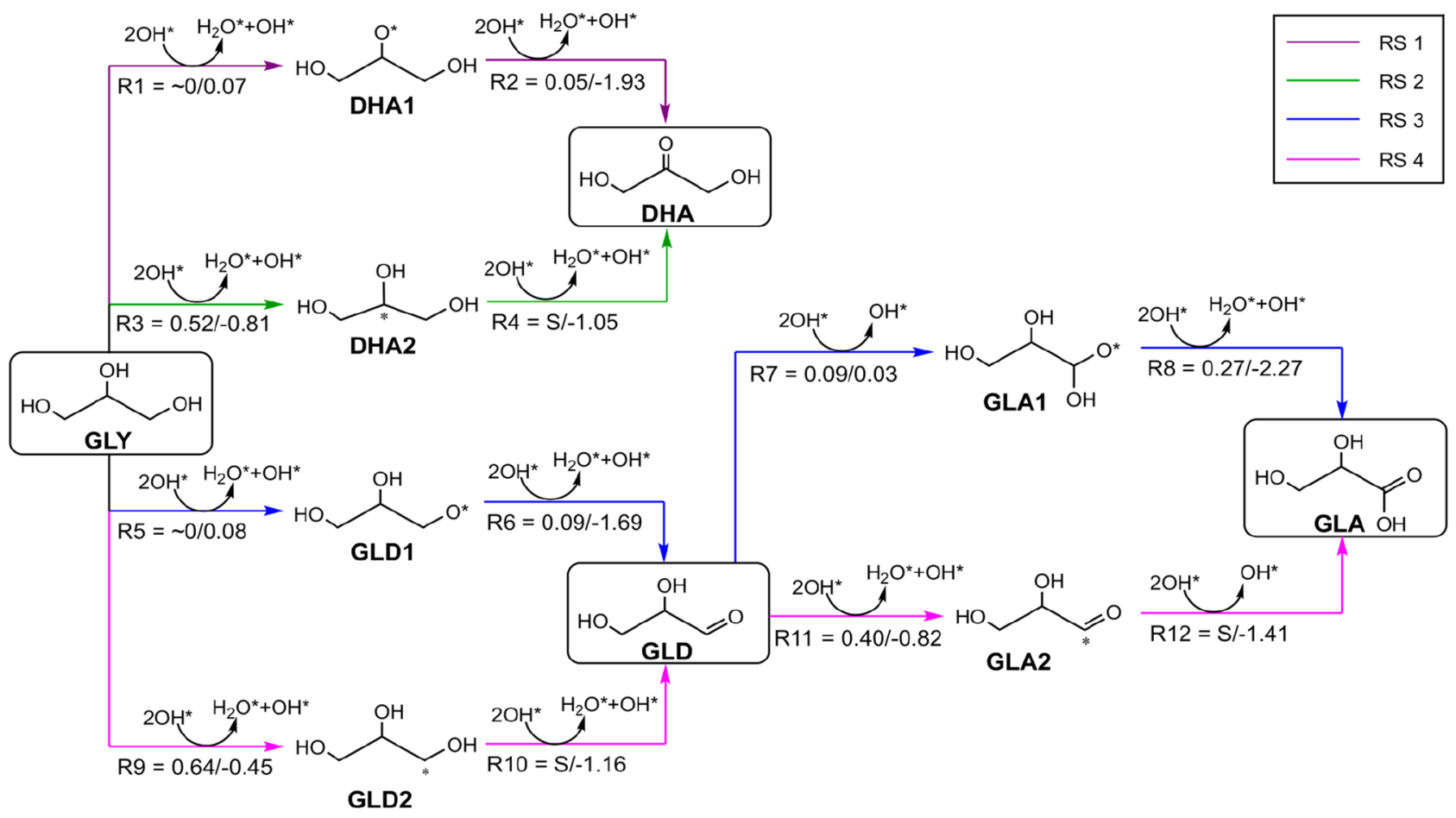

Figure 5. Reaction network for GLY oxidation to dihydroxyacetone (DHA), glyceraldehyde (GLD), and glyceric acid (GLA) in alkaline conditions. Rn beneath the arrow denotes a reaction number along the RS1-RS4 pathways, and the quantities in the parentheses are activation and reaction free energies in $\mathrm{eV}$. Note that, the "S" in R4, R10, and R12 refers to spontaneous reactions for which a transition state structure could not be identified, indicating that these steps are very fast or spontaneous.

barriers are lower than those observed for the first deprotonation reactions. These results show that RS2 is also kinetically the most favorable pathway but it has a high kinetic barrier, $\sim 1 \mathrm{eV}$, for the first oxidation reaction. Both kinetic and thermodynamic perspectives show that the first proton and electron transfer reactions along RS2 and RS4 are likely to be the rate-determining steps for EOG in acidic and neutral media. This finding agrees with experimental results, ${ }^{19}$ where the Tafel slope of $\sim 120 \mathrm{mV} \mathrm{dec}^{-1}$ on the clean Au surface was observed and this high value typically indicates that the first electron transfer is the rate-determining step. Current densities or activities in acidic/neutral media, however, are expected to be small due to the high activation barriers.

Electrocatalytic Oxidation of Glycerol under Alkaline Conditions. In alkaline media, GLA has been identified as the main product or reaction intermediate toward more oxygenated species but the formation of DHA cannot be ruled out a priori based on current experimental data. $1,7,18,19,21,94,95$ Figure 5 summarizes the complete reaction network for all intermediates down to glyceric acid (GLA).

Alkaline EOG Thermodynamics. The alkaline conditions on $\mathrm{Au}(111)$ are represented by explicitly adding $\mathrm{OH}$ groups on the surface. As shown in the Pourbaix diagrams (see Figure 2), the $\mathrm{Au}(111)$ surface has $\sim 1 / 3-1 / 2 \mathrm{ML} \mathrm{OH}$ coverage under highly alkaline conditions for a wide range of potentials. Glycerol adsorption also enhances $\mathrm{OH}$ adsorption. We also note that under alkaline conditions, no specifically adsorbing anions other than $\mathrm{OH}^{-}$are used experimentally. The computational model for Au-catalyzed alkaline EOG must therefore explicitly take into account the influence of coadsorbed $\mathrm{OH}$. To that end, two $\mathrm{OH}$ groups, corresponding to $1 / 6 \mathrm{ML}$ coverage, were added to the $\mathrm{Au}(111)$ surface. The lower 1/6 ML OH coverage was applied to reduce the possible spatial variations of $\mathrm{OH}$ around the glycerol. This coverage also represents a minimal model where one $\mathrm{OH}$ abstracts a proton from the organic reactant and converts it to a water molecule, while the other $\mathrm{OH}$ remains on the surface and stabilizes the reacting species throughout the reaction. To test that the $\mathrm{OH}$ groups on the 1/6 ML surface are necessary and sufficient to reproduce alkaline conditions, we computed the R9 reaction energetics for $1 / 12$ and $1 / 3 \mathrm{ML}$ surfaces (see Figure S8). For the 1/12 ML surface, the reaction energy is $1.05 \mathrm{eV}$ and the reaction barrier is $1.29 \mathrm{eV}$. The barrier is not significantly lower than that on the bare surface demonstrating that at least a $1 / 6 \mathrm{ML} \mathrm{OH}$ coverage is necessary to mimic alkaline conditions. The reaction energy and barrier for the $1 / 3$ ML surface are -0.71 and $0.68 \mathrm{eV}$, respectively. The results from the $1 / 3 \mathrm{ML}$ surface and the 1/6 ML surface are comparable indicating that $1 / 6 \mathrm{ML} \mathrm{OH}$ coverage is sufficient to capture most effects observed under alkaline conditions and to study the effect of $\mathrm{Au}(\mathrm{OH})_{\text {ads }}$ on EOG.

The alkaline reaction mechanism and thermodynamics are summarized in Figure 5 and a more complete thermodynamic profile is presented in Figure S9. The thermodynamics to regenerate the adsorbed $\mathrm{OH}$ is not shown in these figures but can be inferred from the data in Figure 2. We have considered GLY oxidation to DHA and GLD and further to GLA, as GLD is unstable under these reaction conditions. ${ }^{19}$ The reaction thermodynamics in Figures 5 and S8 for EOG intermediates and the energies of adsorbed $\mathrm{OH}$ species were computed separately in different unit cells, i.e., infinitely separated from each other. This approach is necessary because in the presence of adsorbed $\mathrm{OH}$ in the unit cell some EOG intermediates are unstable and, during geometry optimization, they immediately donate a hydrogen atom to the adsorbed $\mathrm{OH}$ group preventing the calculation of elementary thermodynamics. The "infinite- 
separation" assumption is similar to low-coverage assumption often utilized in mean-field microkinetic modeling. In general, the majority of elementary steps are exothermic or at least thermoneutral in alkaline media. We found that the RS2 and RS4 pathways, where the proton is first eliminated from the carbon, are thermodynamically more favorable than removing the proton from the $\mathrm{OH}$ group of GLY. Similar behavior was also observed in acidic and neutral media but under alkaline conditions, surface $\mathrm{OH}$ groups actively participate to abstract the protons and produce water. The thermodynamic analysis alone does not allow conclusions on the activity and product selectivity; an analysis of the reaction kinetics is therefore required.

Alkaline EOG Reaction Kinetics. The natural next step is to address reaction kinetics and compute activation free energies, which are shown in Figure 5. Kinetically feasible DHA and GLD formation is obtained along the RS1 and RS3 pathways, where $\mathrm{H}$ is first removed from $\mathrm{OH}$ and then from $\mathrm{C}$. For both steps, the barriers are smaller than $0.1 \mathrm{eV}$. Along RS2 and $\mathrm{RS} 4, \mathrm{H}$ abstraction takes place in the reverse order, but the first deprotonation free energy barrier is over $0.5 \mathrm{eV}$. Overall, the reaction barriers in alkaline media are significantly lower than those found in acidic or neutral conditions. We attribute this difference to the extremely effective activation of $\mathrm{O}-\mathrm{H}$ bonds by the surface-bound $\mathrm{OH}$ groups, which has also been observed for ethanol oxidation on $\mathrm{Au}(111) .^{5}$ The $\mathrm{Au}(\mathrm{OH})_{\mathrm{ads}^{-}}$ induced low barriers also explain the experimentally observed high activity of Au-catalyzed alkaline EOG. ${ }^{18-20,29}$

We found that the formation of GLA from GLD is highly exergonic and GLA acts as a thermodynamic sink driving the reaction toward further oxidation if the formation of GLD is possible. GLD can easily oxidize to GLA via a nearly barrierless $\mathrm{OH}$ group substitution to GLD (R7) followed by a proton abstraction from the terminal $\mathrm{C}$ (R8) which has an activation energy of $0.27 \mathrm{eV}$. A similar mechanism has been previously proposed based on cyclic voltammetry and online electrochemical mass spectrometry experiments. ${ }^{19}$ For comparison, we also studied the GLD to GLA oxidation on the empty $\mathrm{Au}(111)$ sites not covered with an adsorbed $\mathrm{OH}$. The reaction network and the corresponding energy values are shown in Figure S7 and Table S5, respectively. Interestingly, on the empty $\mathrm{Au}(111)$ sites, step R8 is barrierless, which indicates that maximal alkaline EOG activity is achieved when some elementary steps are catalyzed by $\mathrm{OH}$ groups and others by empty $\mathrm{Au}$ surface sites. Combinations of $\mathrm{OH}$-covered and empty surface sites are possible with the modest $1 / 12-1 / 2$ $\mathrm{ML} \mathrm{OH}$ surface coverages found to be stable under different $\mathrm{pH}$ and potential conditions as shown in Figure 2.

To address the EOG selectivity, the competitive pathways toward DHA and GLD were studied under alkaline conditions. We found that DHA can be easily generated via the RS1 pathway, which is thermodynamically and kinetically feasible in the presence of surface-bound $\mathrm{OH}$ groups (see Figure 5 and Table S5) having a reaction energy of $-1.86 \mathrm{eV}$ and a kinetic barrier below $0.1 \mathrm{eV}$. Forming DHA is therefore very competitive with GLD formation. This means that it is not possible to discern selectivity between these two species in alkaline media and a mixture should be observed in experiments. Experiments, however, have demonstrated that GLA is the sole primary product in Au-catalyzed alkaline $\mathrm{EOG}^{18,19,29}$ suggesting that there is a mechanism for converting DHA to GLD, which then further reacts to form the stable oxidized product GLA. One such pathway is provided by the keto-enol tautomerization between DHA and GLD displayed in Figure S11. To address this possibility, we computed the reaction free energy for this step and found the $\Delta G$ to be $0.01 \mathrm{eV}$ for DHA $\rightleftharpoons \mathrm{GLD}$ in the presence of $1 / 6 \mathrm{ML}$ $\mathrm{OH}$. This indicates that DHA and GLD can be easily interconverted under alkaline conditions as also suggested for thermocatalytic conversion of GLY. ${ }^{94,95}$

\section{DISCUSSION}

The present DFT study provides new atomistic insight into the reaction mechanism and $\mathrm{pH}$ dependence of GLY electrooxidation on $\mathrm{Au}(111)$ at experimentally relevant potentials. Our detailed analysis of reaction thermodynamics and kinetics demonstrates that it is necessary to explicitly take Au-adsorbed $\mathrm{OH}$ species into account when constructing comprehensive computational models for EOG and possibly other electrooxidation reactions. This is particularly important for modeling oxidation reactions in alkaline media, where surface hydroxides or, at higher potentials, oxides are present on a catalyst surface and participate in (electro)catalytic transformations. Interestingly, our results also highlight that chemical steps such as keto-enol tautomerism can play a pivotal role in determining the reaction mechanism and selectivity of electrocatalytic reactions under different reaction conditions.

The first step toward elucidating experimentally observed $\mathrm{pH}$ sensitivity of EOG is to understand the state of the catalyst surface under operating conditions. To achieve this, we constructed Pourbaix diagrams, which demonstrate that $\mathrm{OH}$ coverage on the $\mathrm{Au}(111)$ surface depends explicitly on the $\mathrm{pH}$ in the RHE scale. Under acidic conditions $(\mathrm{pH}=1)$, the surface is clean until $>1.3 \mathrm{~V}_{\mathrm{RHE}}$, at which point a $1 / 12 \mathrm{ML} \mathrm{OH}$ coverage becomes stable. This potential coincides well with the onset potential for acidic EOG on gold. ${ }^{22}$ Under alkaline conditions $(\mathrm{pH}=14), 1 / 3-1 / 2 \mathrm{ML} \mathrm{OH}$ becomes stable at lower potentials, around $>1.3 \mathrm{~V}_{\mathrm{RHE}}$, and is very close to the observed alkaline EOG onset potential. ${ }^{19}$ Under neutral conditions $(\mathrm{pH}=7)$, our simulations predict that $1 / 12,1 / 6$, and $1 / 3 \mathrm{ML} \mathrm{OH}$ coverages are the most favorable $\mathrm{OH}$ adsorption structures becoming stable at potentials $>1.3 \mathrm{~V}_{\mathrm{RHE}}$ again in good agreement with the EOG onset potential. ${ }^{19} \mathrm{We}$ also verified that GLY adsorption is slightly enhanced by the presence $\mathrm{Au}(\mathrm{OH})_{\text {ads }}$ suggesting that hydroxyl adsorption is likely to be accompanied by GLY adsorption and that EOG starts at slightly less oxidizing potentials than required to oxidize Au without GLY. The potential and $\mathrm{pH}$ range for GLY and $\mathrm{OH}$ to be simultaneously adsorbed on $\mathrm{Au}(111)$ sets the conditions where both species available on the surface. The $\mathrm{OH}$ adsorption potentials, however, are similar under varying $\mathrm{pH}$ conditions and the $\mathrm{OH}$ coverage alone cannot be the sole reason for the experimentally observed $\mathrm{pH}$-dependent EOG activity and selectivity. As discussed below, in alkaline EOG experiments $\mathrm{OH}^{-}$is the only anion present in the electrolyte whereas acidic and neutral experiments are carried in the presence of sulfate or perchlorate anions which can significantly influence EOG.

Surface bound $\mathrm{OH}$ groups make all oxidation reactions considered highly exergonic or at least thermoneutral (see Figures 5 and S8) explaining why Au-catalyzed EOG is so favorable under alkaline conditions similar to the electrooxidation of simple alcohols. ${ }^{49,50}$ Our results show that alkaline surface-catalyzed EOG starts with $\mathrm{H}$-abstraction from the $\mathrm{OH}$ group by a surface-bound hydroxide in agreement with the vast majority of experiments. ${ }^{2,18,19,24}$ The surface bound $\mathrm{OH}$ 


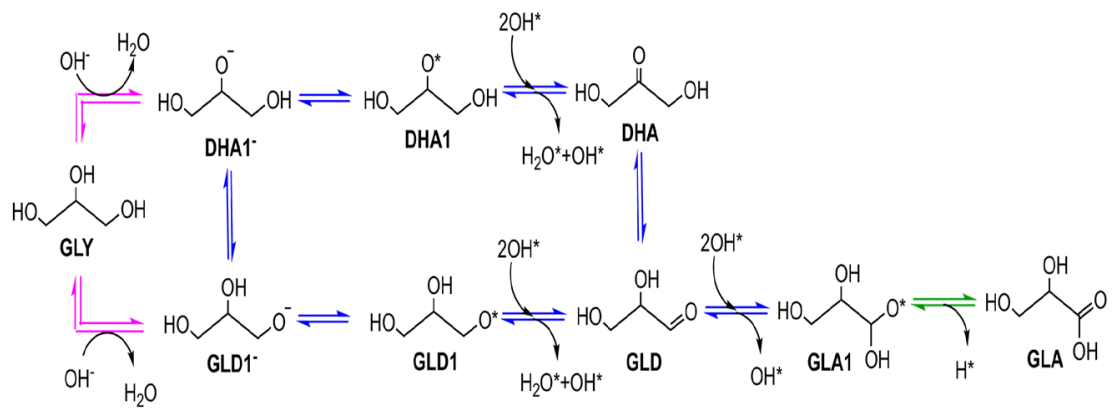

Figure 6. Optimal EOG reaction pathway in alkaline conditions on the $\mathrm{Au}(111)$ surface. The magenta arrows indicate base-catalyzed (aqueous $\left.\mathrm{OH}^{-}\right)$reactions producing solvated $\mathrm{DHA1} 1^{-}$and $\mathrm{GLD1}^{-}$species. The blue arrows indicate the reaction steps assisted by an $\mathrm{Au}(\mathrm{OH})_{\text {ads }}$ active site whereas the green arrow denotes a reaction on a Au active site.

species mediate the oxidation of primary or secondary $\mathrm{C}-\mathrm{OH}$ groups of GLY as they provide a basic site to remove the slightly acidic proton from the alcohol functional group. This is reflected in the very small activation free energies for the pathways leading to either DHA, GLD, or GLA. The formation and presence of $\mathrm{Au}(\mathrm{OH})_{\text {ads }}$ is therefore an integral part of the EOG chemistry substantially modifying the kinetics and thermodynamics. Yet, the formation of these hydroxide species is spontaneous only at relatively oxidizing potentials above $\sim 1$ $\mathrm{V}_{\mathrm{RHE}}$ as shown by the Pourbaix diagram for GLY (Figure S15) and surface hydroxides in Figure 2. Hence, our explanation for the fairly high onset potentials observed experimentally for alkaline EOG on $\mathrm{Au}^{18,19}$ is that the increase in activity coincides with GLY adsorption and the formation of $\mathrm{Au}(\mathrm{OH})_{\text {ads }}$ making EOG feasible.

The results also show that under alkaline conditions, the $\mathrm{Au}(111)$ surface has moderate $\mathrm{OH}$ coverage (1/3-1/2 ML) and contains two types of reaction sites, i.e., $\mathrm{Au}(\mathrm{OH})_{\text {ads }}$ and empty $\mathrm{Au}$, both of which are needed for GLY conversion. The majority of steps from GLY to GLA along the reaction pathway RS3 proceed via the $\mathrm{OH}$-assisted route except the last step from GLA1 to GLA, which is thermodynamically and kinetically preferred on an empty Au site rather than a $\mathrm{Au}(\mathrm{OH})_{\text {ads }}$ site. The surface-catalyzed alkaline EOG activity can thus be optimized if two different active sites, $\mathrm{Au}$ and $\mathrm{Au}(\mathrm{OH})_{\mathrm{ads}}$, are present. It can therefore be concluded that under alkaline conditions the optimal EOG reaction on $\mathrm{Au}$ operates via a two-site mechanism as previously suggested for methanol oxidation. ${ }^{96}$ Such a dual-site mechanism is also supported by experimental ${ }^{5,18}$ and computational ${ }^{5,12,57}$ studies of thermocatalytic metal-catalyzed alcohol oxidation in alkaline conditions. The dual-site mechanism has also been proposed for the thermocatalytic production of either DHA or GLD over $\mathrm{Pt}$ but in this case the generation of $\mathrm{Pt}-\mathrm{OH}$ sites is unfavorable. $^{57}$

The combined thermodynamic, kinetic, and mechanistic analyses resolve some open questions regarding the $\mathrm{Au}$ catalyzed EOG mechanism. The computational results suggest that, in alkaline conditions, the oxidation of GLY begins with the abstraction of hydrogen from an $\mathrm{O}-\mathrm{H}$ bond followed by subsequent deprotonation of $\mathrm{C}-\mathrm{H}$. Both deprotonation reactions are found to be easily mediated by either surface hydroxides or gold atoms. An alternative pathway supported by experiments ${ }^{18}$ is that solution-phase $\mathrm{OH}^{-}$first deprotonates GLY to GLD1 in solution followed by GLD1 (glycerolate) adsorption on the surface. For these reactions, a Hammett relationship was demonstrated between the alcohol reactivities and their $\mathrm{p} K_{\mathrm{a}}$ values ${ }^{18}$ such that a lower $\mathrm{p} K_{\mathrm{a}}$ value corresponds to higher alcohol oxidation reactivity. This suggests the solution-phase $\mathrm{OH}^{-}$ions may play a greater role for the overall activity/reactivity than the $\mathrm{Au}(\mathrm{OH})_{\text {ads }}$ intermediates. It is also possible the local solution $\mathrm{pH}$ is even higher near the electrode in the (outer) Helmholtz layer such that GLY can be efficiently deprotonated. As the charged glycerolate adsorbs more strongly than the neutral GLY, ${ }^{54}$ higher EOG activity under alkaline conditions can partially be attributed to more exergonic adsorption of the reactant. The stronger adsorption was also confirmed as the computed GLD1 adsorption energy is $-1.35 \mathrm{eV}$ which is $\sim 0.6 \mathrm{eV}$ stronger than GLY adsorption. Therefore, we agree with experiments that the GLY oxidation to GLD1 is most likely catalyzed by aqueous $\mathrm{OH}^{-}$, i.e., a basecatalyzed reaction. While the presence of solvent-phase $\mathrm{OH}^{-}$ can induce stronger adsorption, base $\left(\mathrm{OH}^{-}\right)$influenced catalysis can only occur when the (local) $\mathrm{pH}$ is close to the glycerol $\mathrm{pK}_{\mathrm{a}}$ at 14.15. In contrast, adsorbed $\mathrm{OH}$ species can participate in EOG even under more acidic conditions. Furthermore, abstracting a second proton from GLD1 would result in an anionic intermediate and GLD1 likely has a very high $\mathrm{p} K_{\mathrm{a}}$. The $\mathrm{Au}$ or $\mathrm{Au}(\mathrm{OH})_{\text {ads }}$ under alkaline conditions are therefore needed to accomplish the conversion of GLD1 to GLD which proceeds easily under alkaline conditions. Further oxidation of GLD to GLA may proceed either through $\mathrm{Au}(\mathrm{OH})_{\mathrm{ads}}$ on the surface (Figure 2) or solvated $\mathrm{OH}^{-}$base catalysis in the presence of oxygen. ${ }^{18,19}$ While experimental data led to the conclusion that base catalysis is the dominant

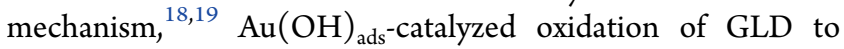
GLA on the surface is both kinetically and thermodynamically facile. GLD desorption is an endergonic process (see Figure 4) and has a higher barrier than GLD $\rightarrow$ GLAl oxidation in the presence of adsorbed $\mathrm{OH}$; therefore, the formation of GLA is expected to proceed through surface catalysis.

Based on our computational results and previous experimental studies, ${ }^{54}$ we propose the following mechanism where base and surface catalysis act cooperatively under alkaline conditions as shown in Figure 6. (1) The alkaline solution promotes glycerolate (GLD1) formation which adsorbs on the surface more strongly than glycerol. (2) Efficient conversion of GLD1 $\rightarrow$ GLD requires that $\mathrm{Au}(\mathrm{OH})_{\text {ads }}$ participates in the process. (3) Further oxidation of GLD to GLA1 also takes place on the surface through $\mathrm{Au}(\mathrm{OH})_{\mathrm{ads}}$ (4) GLA1 $\rightarrow$ GLA occurs on the pure Au sites. Steps 1 and 2 are the same as previously proposed based on experiments while steps 3 and 4 differ. $^{18,19}$ Our mechanism also differs from the fully surfacecatalyzed EOG mechanism recently suggested. ${ }^{54}$ The proposed alkaline EOG pathway on gold consists of cooperative base- 
surface catalysis where some steps are catalyzed by aqueous $\mathrm{OH}^{-}, \mathrm{Au}(\mathrm{OH})_{\mathrm{ads}}$, empty $\mathrm{Au}$ sites.

In the absence of $\mathrm{Au}(\mathrm{OH})_{\mathrm{ads}}$, EOG proceeds differently, taking place on the $\mathrm{Au}$ sites or in the presence of low $\mathrm{OH}$ coverage at high oxidation potentials. According to the thermodynamic and kinetic analyses, DHA is the main product in agreement with previous calculations ${ }^{53}$ and experiments at low oxidation potentials and acidic conditions, ${ }^{22}$ but the rate/ current density is expected to be small due to the relatively high kinetic barriers. Our results show that for acidic EOG at low oxidation potentials (below $1.3 \mathrm{~V}_{\mathrm{RHE}}$ at $\mathrm{pH}=1$ ), $\mathrm{DHA}$ is produced via secondary $\mathrm{C}-\mathrm{H}$ elimination in agreement with a previous study. ${ }^{22}$ Experimentally, a marked increase in current densities was observed at oxidizing potentials of 1.2-1.5 $\mathrm{V}_{\mathrm{RHE}}$ at $\mathrm{pH}=1$ but could not be rationalized. ${ }^{22}$ We ascribe this to the presence of $\mathrm{OH}$ on the surface under these conditions (see Figure 2), which significantly increases EOG activity as discussed above for the alkaline mechanism. In acidic solutions, however, the base catalysis component is absent and we propose that EOG is fully surface catalyzed in accordance with present mechanistic understanding. ${ }^{54}$ Furthermore, acidic EOG seems sensitive to the nature of the counteranion, as EOG proceeds only in $\mathrm{HClO}_{4}{ }^{22}$ on $\mathrm{Au}$ but not in $\mathrm{H}_{2} \mathrm{SO}_{4}{ }^{19}$ This sensitivity is likely related to the specific adsorption of $\mathrm{SO}_{4}{ }^{2-}$ affecting $\mathrm{Au}(\mathrm{OH})_{\mathrm{ads}}$ formation: ${ }^{40} \mathrm{Au}$ surfaces have long been believed to be inactive toward acidic EOG, ${ }^{16,19}$ which might be due to $\mathrm{SO}_{4}{ }^{2-}$ adsorption as well as low EOG activity and selectivity resulting from the high reaction barriers in the absence of proton acceptors, such as hydroxides, on the surface. This hypothesis can be tested experimentally by doping Au with more basic metals or by decorating $\mathrm{Au}$ with basic oxides ${ }^{2,97-101}$ or using $\mathrm{SO}_{4}{ }^{2-}$ or $\mathrm{ClO}_{4}{ }^{-}$free solutions.

Our results predict that a wide range of $\mathrm{OH}$ coverages are stable at potentials above $\sim 1.35 \mathrm{~V}_{\mathrm{RHE}}$ at $\mathrm{pH}=7$. Given the role of $\mathrm{OH}$ in facilitating EOG, our calculations suggest the current density under neutral conditions is negligible below $1.35 \mathrm{~V}_{\mathrm{RHE}}$ but should increase above this potential. Our calculated adsorption potentials for higher $\mathrm{OH}$ surface coverages expected under alkaline conditions are aligned with the experimentally observed decrease in EOG onset potential as the $\mathrm{pH}$ increases. ${ }^{19,102}$ The prediction of higher EOG onset potentials below $1.35 \mathrm{~V}_{\mathrm{RHE}}$ is also consistent with the low current density observed under neutral conditions. The 1/6 and $1 / 3 \mathrm{ML} \mathrm{OH}$ coverages are therefore expected to catalyze GLD formation via primary $\mathrm{O}-\mathrm{H}$ elimination at high potentials $\left(>1.35 \mathrm{~V}_{\mathrm{RHE}}\right)$ in neutral media following the same mechanism observed for alkaline EOG. This reasoning is consistent with the experimental suggestion ${ }^{19}$ that EOG follows similar pathways under neutral and alkaline conditions. Our results, however, cannot fully explain the drastic difference in EOG activity between neutral and alkaline conditions that is experimentally observed above $\mathrm{OH}$ adsorption potentials. As we have shown that adsorbed hydroxides lower the barriers for EOG, to explain this kinetic difference, we suspect the low reaction rates or currents are due to the $\mathrm{SO}_{4}{ }^{2-}$ and $\mathrm{ClO}_{4}{ }^{-}$ anions used in neutral EOG experiments. ${ }^{19,102}$ Both anions are known to specifically adsorb on gold surfaces between 0.2 and $1.05 \mathrm{~V}_{\mathrm{RHE}}$ and to reach $0.15-0.2 \mathrm{ML}$ surface coverages. ${ }^{40,41}$ The low currents can be explained by combining the fact that $\mathrm{SO}_{4}{ }^{2-}$ is adsorbed on the surface at potentials up to $1.2 \mathrm{~V}_{\mathrm{RHE}}$ at $\mathrm{pH}=0$, after which Au surface oxidation begins, ${ }^{40}$ with the anions' suspected role in blocking GLY or GLD adsorption. ${ }^{102}$
Surface-enhanced IR absorption spectroscopy measurements have also shown that $\mathrm{Au}(\mathrm{OH})_{\text {ads }}$ and adsorbed $\mathrm{SO}_{4}{ }^{2-}$ can coexist up to $1.5 \mathrm{~V}_{\mathrm{RHE}}$ under neutral conditions which coincides well with our calculated $\mathrm{OH}$ adsorption potential at $\mathrm{pH}=7$ and the experimental onset potential around 1.2-1.3 $\mathrm{V}_{\mathrm{RHE}}$. We therefore suggest the small non-Nernstian shifts in the $\mathrm{OH}$ coverage combined with specific anion adsorption are the reasons for low EOG activity under neutral conditions. Verification of this suggestion calls for computational studies of EOG for coadsorbed $\mathrm{OH}+$ sulfate/perchlorate structures.

In addition to $\mathrm{pH}$ effects influencing base catalysis (through aqueous $\mathrm{OH}^{-}$) and surface catalysis (through $\mathrm{Au}(\mathrm{OH})_{\text {ads }}$ ), the $\mathrm{pH}$ was found to affect EOG selectivity via keto-enol tautomerism between DHA and GLD. The computed reaction free energy demonstrates that DHA-GLD tautomerism is thermoneutral under alkaline conditions and offers an alternative pathway to form GLD from DHA. Once formed, GLD can easily oxidize to highly stable GLA, which acts as a thermodynamic sink for EOG as shown in Figures 5 and S8. This observation explains the experimentally observed activity and selectivity toward GLA and absence of DHA under alkaline conditions. Interestingly, the tautomerization is thermodynamically less favorable under acidic conditions on the bare Au surface since $\Delta G$ is $0.24 \mathrm{eV}$ (see Figure S11). Alkaline conditions also enhance the tautomerism kinetics as the adsorbed $\mathrm{OH}$ species can cleave the $\mathrm{C}-\mathrm{H}$ bond while a water molecule or another EOG intermediate simultaneously donates a proton to form the entiol intermediate (see Figure S11). ${ }^{103}$ GLD formation directly from GLY in acidic media is less favorable than DHA formation and the absence of efficient hydrogen acceptors would make the reaction kinetically sluggish. As a result, GLD cannot form easily in acidic environments and Au-catalyzed EOG should lead only to DHA and DHA-derived products as supported by previous experimental and computational studies. ${ }^{22}$ Overall, our findings on the tautomerism in EOG agree with experimental results on thermal GLY conversion, ${ }^{94,95}$ where the pivotal role of the DHA-GLD keto-enol tautomerism for $\mathrm{pH}$-dependent selectivity has been reported at high $\mathrm{pH}$.

After obtaining robust mechanistic understanding of EOG, we briefly address how this could be utilized in catalyst screening. We attempted to establish linear scaling relations between adsorption energies of initial and final states of elementary steps as well as the Brønsted-Evans-Polanyi (BEP) relationships between the activation and reaction energies. The correlations obtained are presented in Figure S13. For EOG on the clean $\mathrm{Au}(111)$ surface, mimicking acidic and neutral conditions, excellent scaling and BEP relationships were obtained with the $R^{2}$ value of $\sim 0.96$ (see Figure S11a,b). This highlights that one descriptor, the reaction energy of an elementary step, can successfully determine EOG reaction barriers. Unfortunately, on the hydroxylated $\mathrm{Au}(111)$ surface neither adsorption nor activation energies are correlated with reaction energies (see Figure $\mathrm{S} 11 \mathrm{c}, \mathrm{d}$ ). This indicates that $\mathrm{H}_{2} \mathrm{O}$ or/and $\mathrm{OH}$ configurations close to a particular glycerol derivative influence the reaction kinetics and thermodynamics through direct adsorbate-adsorbate interactions, which are absent from clean surfaces or mean-field models. As previously proposed, ${ }^{104}$ a possible approach to explore the role of these coverage effects would be to construct $\mathrm{OH}$-coverage Pourbaix diagrams to identify the stable surface phase for each adsorbate separately and then use these structures for determining reaction kinetics and thermodynamics. Regardless, alkaline 
conditions require more comprehensive computational models, considering the role of $\mathrm{OH}$ groups in both solution and on the surface, or alternative mechanistic pathways such as ketoenol tautomerism, to describe the reaction environment and examine EOG reaction pathways. Furthermore, the effect of anion/OH coadsorption should be included in the models to address the electrolyte and $\mathrm{pH}$ effects. We anticipate that such species and reactions should be more thoroughly taken into account when addressing the electrocatalytic conversions of complex molecules under reaction conditions.

\section{CONCLUSIONS}

We performed an extensive computational study to explain the experimentally observed potential and $\mathrm{pH}$ dependency of $\mathrm{Au}-$ catalyzed glycerol electro-oxidation. Pourbaix diagrams were constructed to analyze the variation of adsorbed $\mathrm{OH}$ groups as a function of the electrode potential and solution $\mathrm{pH}$. Our calculations have shown a non-Nernstian shift for $1 / 3-1 / 2$ $\mathrm{ML} \mathrm{OH}$ coverage and increased EOG activity with $\mathrm{OH}$ on the surface which compares well with the activity observed on $\mathrm{Au}$ surfaces under alkaline conditions. Conversely, $\mathrm{OH}$ adsorbs at slightly higher potentials under acidic conditions and the clean surface does not favor EOG which also agrees with experiments. Although our calculations indicate similar activity between neutral and alkaline conditions above $\mathrm{OH}$ adsorption potentials, previous experiments suggest typical neutral solution electrolytes, sulfate and perchlorate, obstruct glycerol adsorption. Therefore, at experimentally relevant potentials, the $\mathrm{Au}(111)$ surface exists with a modest $\mathrm{OH}$ coverage without any specifically adsorbed anions under alkaline conditions whereas $\mathrm{OH}+$ sulfate/perchlorate coadsorbed structures or a lower $\mathrm{OH}$ coverage may exist under acidic conditions.

EOG thermodynamics and kinetics were investigated on both the pristine and $\mathrm{OH}$-covered $\mathrm{Au}$ surfaces, mimicking acidic or low potential and alkaline or high potential conditions, respectively. We found that under acidic conditions glycerol conversion to dihydroxyacetone is both kinetically and thermodynamically more favorable than the conversion to glyceraldehyde, which agrees with the experimentally observed selectivity. Poor EOG activity of $\mathrm{Au}$ reported under acidic conditions, however, results from the kinetic hindrance of dihydroxyacetone formation. Under alkaline conditions, the presence of $\mathrm{OH}$ groups makes the glyceraldehyde formation and further oxidation to glyceric acid feasible. The reaction barriers on the $\mathrm{OH}$-covered $\mathrm{Au}(111)$ surface are substantially lower than those on the pristine surface explaining the higher activity under alkaline conditions. The experimentally observed selectivity toward glyceric acid in alkaline media is attributed to fast reaction kinetics and favorable thermodynamics of glyceraldehyde oxidation to glyceric acid. Furthermore, our results support the existence of a dual active site under alkaline conditions and at low $\mathrm{OH}$ coverage allowing some deprotonation steps to be $\mathrm{Au}(\mathrm{OH})_{\text {ads }}$ catalyzed while others are surface $(\mathrm{Au})$ catalyzed. We also show that the chemical keto-enol tautomerism between dihydroxyacetone and glyceraldehyde is pivotal in determining the electrocatalytic selectivity under alkaline conditions. This provides a pathway to convert dihydroxyacetone to glyceric acid and explains why dihydroxyacetone is observed at high $\mathrm{pH}$. Under acidic conditions, the keto-enol tautomerism is thermodynamically unfavorable and therefore dihydroxyacetone cannot be easily transformed to glyceraldehyde or glyceric acid. Altogether, we have provided consistent mechanistic understanding for the experimentally observed EOG activity and selectivity on $\mathrm{Au}$, but this has required explicit consideration of $\mathrm{pH}$ and potential effects on $\mathrm{OH}$ coverage, thermodynamics, kinetics, and the reaction mechanism as well as invoking the experimentally verified coadsorption of $\mathrm{OH}$ and perchlorate/sulfate under acidic and neutral conditions.

Beyond the Au-catalyzed EOG, our results combined with previous experiments highlight that the effect of $\mathrm{pH}, \mathrm{OH}$ surface coverage, and the electrolyte must be explicitly included in computational studies of electrocatalytic oxidation reactions. The presence of adsorbed $\mathrm{OH}$ qualitatively and quantitatively changes the elementary thermodynamics, kinetics, and reaction mechanisms. The experimental results can only be explained by explicitly accounting for the effect of reaction conditions. This conclusion has potentially wide implications on future computational studies of electrocatalytic activity and selectivity. In particular, alkaline oxidation reactions are likely to be explicitly dependent on the $\mathrm{pH}$ and $\mathrm{OH}$-surface coverage and they cannot be fully understood with overly simplified reaction models, thermodynamics alone, or linear free energy relationships, therefore calling for more comprehensive computational approaches.

\section{ASSOCIATED CONTENT}

\section{SI Supporting Information}

The Supporting Information is available free of charge at https://pubs.acs.org/doi/10.1021/acscatal.1c03788.

$\mathrm{OH}$ adsorption from constant potential calculations, computation of Gibbs free energies, glycerol conformers, adsorption configurations, adsorption energies, thermodynamics of neutral/acidic/alkaline EOG, keto-enol tautomerization of acidic/neutral, scaling correlation plots, discussion on the reactivity of $\mathrm{OH}$ groups, and transition state structures (PDF)

\section{AUTHOR INFORMATION}

\section{Corresponding Author}

Karoliina Honkala - Department of Chemistry, Nanoscience Center, University of Jyväskylä, FI-40014 Jyväskylä, Finland; (1) orcid.org/0000-0002-3166-1077; Phone: +358 408053 686; Email: karoliina.honkala@jyu.fi

\section{Authors}

Anand M. Verma - Department of Chemistry, Nanoscience Center, University of Jyväskylä, FI-40014 Jyväskylä, Finland

Laura Laverdure - Department of Chemistry, Nanoscience Center, University of Jyväskylä, FI-40014 Jyväskylä, Finland

Marko M. Melander - Department of Chemistry, Nanoscience Center, University of Jyväskylä, FI-40014 Jyväskylä,

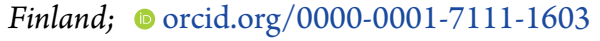

Complete contact information is available at: https://pubs.acs.org/10.1021/acscatal.1c03788

\section{Notes}

The authors declare no competing financial interest. The xyz coordinates can be found on University of Jyväskylä's gitlab account: https://gitlab.jyu.fi/mamimela/glycerol_data.

\section{ACKNOWLEDGMENTS}

The work was supported by the Academy of Finland through projects 317739 (A.M.V., L.L., M.M.M., and K.H.) and 307853 (M.M.M.). The computational resources were provided by the 
CSC-IT Center for Science, Espoo, Finland (https://www.csc. fi/en/). A.M.V. and M.M.M. thank Prof. H. A. Hansen for the constructive discussion on surface Pourbaix diagrams.

\section{REFERENCES}

(1) Dodekatos, G.; Schünemann, S.; Tüysüz, H. Recent advances in thermo-, photo-, and electrocatalytic glycerol oxidation. ACS Catal. 2018, 8, 6301-6333.

(2) Villa, A.; Jouve, A.; Sanchez Trujillo, F. J.; Motta, D.; Prati, L.; Dimitratos, N. Exploring the effect of $\mathrm{Au} / \mathrm{Pt}$ ratio on glycerol oxidation in presence and absence of a base. Catalysts 2018, 8, 54 .

(3) Quispe, C. A.; Coronado, C. J.; Carvalho, J. A. Glycerol: Production, consumption, prices, characterization and new trends in combustion. Renew. Sust. Energy Rev. 2013, 27, 475-493.

(4) Bozell, J. J.; Petersen, G. R. Technology development for the production of biobased products from biorefinery carbohydrates-the US Department of Energy's “top 10” revisited. Green Chem. 2010, 12, 539-55.

(5) Zope, B. N.; Hibbitts, D. D.; Neurock, M.; Davis, R. J. Reactivity of the gold/water interface during selective oxidation catalysis. Science 2010, 330, 74-78.

(6) Schünemann, S.; Schüth, F.; Tüysüz, H. Selective glycerol oxidation over ordered mesoporous copper aluminum oxide catalysts. Catal. Sci. Technol. 2017, 7, 5614-5624.

(7) Liu, S. S.; Sun, K. Q.; Xu, B. Q. Specific selectivity of Aucatalyzed oxidation of glycerol and other $\mathrm{C}_{3}$-polyols in water without the presence of a base. ACS Catal. 2014, 4, 2226-2230.

(8) Villa, A.; Dimitratos, N.; Chan-Thaw, C. E.; Hammond, C.; Prati, L.; Hutchings, G. J. Glycerol oxidation using gold-containing catalysts. Acc. Chem. Res. 2015, 48, 1403-1412.

(9) Yang, P.; Pan, J.; Liu, Y.; Zhang, X.; Feng, J.; Hong, S.; Li, D. Insight into the role of unsaturated coordination $\mathrm{O}_{2 c}-T_{5 c}-O_{2 c}$ sites on selective glycerol oxidation over $\mathrm{AuPt} / \mathrm{TiO}_{2}$ catalysts. ACS Catal. 2019, 9, 188-199.

(10) Hirasawa, S.; Watanabe, H.; Kizuka, T.; Nakagawa, Y.; Tomishige, K. Performance, structure and mechanism of Pd-Ag alloy catalyst for selective oxidation of glycerol to dihydroxyacetone. J. Catal. 2013, 300, 205-216.

(11) Liu, B.; Greeley, J. Decomposition pathways of glycerol via C$\mathrm{H}, \mathrm{O}-\mathrm{H}$, and $\mathrm{C}-\mathrm{C}$ bond scission on $\mathrm{Pt}(111)$ : A density functional theory study. J. Phys. Chem. C 2011, 115, 19702-19709.

(12) Chen, Y.; Salciccioli, M.; Vlachos, D. G. An efficient reaction pathway search method applied to the decomposition of glycerol on platinum. J. Phys. Chem. C 2011, 115, 18707-18720.

(13) Liu, B.; Greeley, J. A density functional theory analysis of trends in glycerol decomposition on close-packed transition metal surfaces. Phys. Chem. Chem. Phys. 2013, 15, 6475-6485.

(14) You, K. E.; Ammal, S. C.; Lin, Z.; Wan, W.; Chen, J. G.; Heyden, A. Understanding the effect of $\mathrm{Mo}_{2} \mathrm{C}$ support on the activity of $\mathrm{Cu}$ for the hydrodeoxygenation of glycerol. J. Catal. 2020, 388, 141-153.

(15) Wan, W.; Ammal, S. C.; Lin, Z.; You, K. E.; Heyden, A.; Chen, J. G. Controlling reaction pathways of selective $\mathrm{C}-\mathrm{O}$ bond cleavage of glycerol. Nat. Commun. 2018, 9, 4612.

(16) Beden, B.; Çetin, I.; Kahyaoglu, A.; Takky, D.; Lamy, C. Electrocatalytic oxidation of saturated oxygenated compounds on gold electrodes. J. Catal. 1987, 104, 37-46.

(17) Roquet, L.; Belgsir, E. M.; Léger, J. M.; Lamy, C. Kinetics and mechanisms of the electrocatalytic oxidation of glycerol as investigated by chromatographic analysis of the reaction products: Potential and pH effects. Electrochim. Acta 1994, 39, 2387-2394.

(18) Kwon, Y.; Lai, S. C.; Rodriguez, P.; Koper, M. T. Electrocatalytic oxidation of alcohols on gold in alkaline media: Base or gold catalysis? J. Am. Chem. Soc. 2011, 133, 6914-6917.

(19) Kwon, Y.; Schouten, K. J. P.; Koper, M. T. Mechanism of the catalytic oxidation of glycerol on polycrystalline gold and platinum electrodes. ChemCatChem. 2011, 3, 1176-1185.
(20) Kwon, Y.; Birdja, Y.; Spanos, I.; Rodriguez, P.; Koper, M. T. Highly selective electro-oxidation of glycerol to dihydroxyacetone on platinum in the presence of bismuth. ACS Catal. 2012, 2, 759-764. (21) Rahim, S. A. N. M.; Lee, C. S.; Abnisa, F.; Aroua, M. K.; Daud, W. A. W.; Cognet, P.; Pérès, Y. A review of recent developments on kinetics parameters for glycerol electrochemical conversion - A byproduct of biodiesel. Sci. Total Environ. 2020, 705, 135137.

(22) Valter, M.; Busch, M.; Wickman, B.; Grönbeck, H.; Baltrusaitis, J.; Hellman, A. Electrooxidation of glycerol on gold in acidic medium: A combined experimental and DFT study. J. Phys. Chem. C 2018, 122, 10489-10494.

(23) Sandrini, R. M.; Sempionatto, J. R.; Tremiliosi-Filho, G.; Herrero, E.; Feliu, J. M.; Souza-Garcia, J.; Angelucci, C. A. Electrocatalytic oxidation of glycerol on platinum single crystals in alkaline media. ChemElectroChem. 2019, 6, 4238.

(24) Coutanceau, C.; Baranton, S.; Kouamé, R. S. Selective electrooxidation of glycerol into value-added chemicals: A short overview. Front. Chem. 2019, 7, 100.

(25) Kim, H. J.; Kim, Y.; Lee, D.; Kim, J. R.; Chae, H. J.; Jeong, S. Y.; Kim, B. S.; Lee, J.; Huber, G. W.; Byun, J.; Kim, S.; Han, J. Coproducing value-added chemicals and hydrogen with electrocatalytic glycerol oxidation technology: Experimental and technoeconomic investigations. ACS Sustain. Chem. Eng. 2017, 5, 66266634.

(26) Han, X.; Sheng, H.; Yu, C.; Walker, T. W.; Huber, G. W.; Qiu, J.; Jin, S. Electrocatalytic oxidation of glycerol to formic acid by $\mathrm{CuCo}_{2} \mathrm{O}_{4}$ spinel oxide nanostructure catalysts. ACS Catal. 2020, 10, 6741-6752.

(27) Pagliaro, M. V.; Bellini, M.; Bevilacqua, M.; Filippi, J.; Folliero, M. G.; Marchionni, A.; Miller, H. A.; Oberhauser, W.; Caporali, S.; Innocenti, M.; Vizza, F. Carbon supported Rh nanoparticles for the production of hydrogen and chemicals by the electroreforming of biomass-derived alcohols. RSC Adv. 2017, 7, 13971-13978.

(28) Garlyyev, B.; Xue, S.; Fichtner, J.; Bandarenka, A. S.; Andronescu, C. Prospects of value-added chemicals and hydrogen via electrolysis. ChemSusChem 2020, 13, 2513-2521.

(29) Kwon, Y.; Koper, M. T. Combining voltammetry with HPLC: Application to electro-oxidation of glycerol. Anal. Chem. 2010, 82, 5420-5424.

(30) Jeffery, D. Z.; Camara, G. A. The formation of carbon dioxide during glycerol electrooxidation in alkaline media: First spectroscopic evidences. Electrochem. commun 2010, 12, 1129-1132.

(31) Bambagioni, V.; Bianchini, C.; Marchionni, A.; Filippi, J.; Vizza, F.; Teddy, J.; Serp, P.; Zhiani, M. Pd and Pt-Ru anode electrocatalysts supported on multi-walled carbon nanotubes and their use in passive and active direct alcohol fuel cells with an anion-exchange membrane (alcohol = methanol, ethanol, glycerol). J. Power Sources 2009, 190, 241-251.

(32) Simões, M.; Baranton, S.; Coutanceau, C. Enhancement of catalytic properties for glycerol electrooxidation on $\mathrm{Pt}$ and $\mathrm{Pd}$ nanoparticles induced by $\mathrm{Bi}$ surface modification. Appl. Catal., B 2011, 110, 40-49.

(33) Garcia, A. C.; Kolb, M. J.; Van Nierop Y Sanchez, C.; Vos, J.; Birdja, Y. Y.; Kwon, Y.; Tremiliosi-Filho, G.; Koper, M. T. Strong impact of platinum surface structure on primary and secondary alcohol oxidation during electro-oxidation of glycerol. ACS Catal. 2016, 6, 4491-4500.

(34) Oliveira, V. L.; Morais, C.; Servat, K.; Napporn, T. W.; Tremiliosi-Filho, G.; Kokoh, K. B. Glycerol oxidation on nickel based nanocatalysts in alkaline medium - Identification of the reaction products. J. Electroanal. Chem. 2013, 703, 56-62.

(35) Oliveira, V. L.; Morais, C.; Servat, K.; Napporn, T. W.; Tremiliosi-Filho, G.; Kokoh, K. B. Studies of the reaction products resulted from glycerol electrooxidation on Ni-based materials in alkaline medium. Electrochim. Acta 2014, 117, 255-262.

(36) Ottoni, C. A.; da Silva, S. G.; De Souza, R. F.; Neto, A. O. Glycerol oxidation reaction using $\mathrm{PdAu} / \mathrm{C}$ electrocatalysts. Ionics 2016, 22, 1167-1175. 
(37) Da Silva, R. G.; Aquino Neto, S.; Kokoh, K. B.; De Andrade, A. $\mathrm{R}$. Electroconversion of glycerol in alkaline medium: From generation of energy to formation of value-added products. J. Power Sources 2017, $351,174-182$.

(38) Diaz-Morales, O.; Calle-Vallejo, F.; De Munck, C.; Koper, M. T. Electrochemical water splitting by gold: Evidence for an oxide decomposition mechanism. Chem. Sci. 2013, 4, 2334-2343.

(39) Rodriguez, P.; Koper, M. T. Electrocatalysis on gold. Phys. Chem. Chem. Phys. 2014, 16, 13583-13594.

(40) Zhumaev, U.; Rudnev, A. V.; Li, J.-F.; Kuzume, A.; Vu, T.-H.; Wandlowski, T. Electro-oxidation of $\mathrm{Au}(111)$ in contact with aqueous electrolytes: New insight from in situ vibration spectroscopy. Electrochim. Acta 2013, 112, 853-863.

(41) Strobl, J. R.; Scherson, D. The adsorption of perchlorate, sulfate, selenate and water on $\mathrm{Au}(111)$-textured electrodes from aqueous solutions: Simultaneous voltammetric, optical and microgravimetric studies. Electrochim. Acta 2021, 394, 139107.

(42) Zhumaev, U.; Lai, A.; Pobelov, I.; Kuzume, A.; Rudnev, A.; Wandlowski, T. Quantifying perchlorate adsorption on $\mathrm{Au}(111)$ electrodes. Electrochim. Acta 2014, 146, 112-118.

(43) Velázquez-Hernández, I.; Zamudio, E.; Rodríguez-Valadez, F. J.; García-Gómez, N. A.; Álvarez-Contreras, L.; Guerra-Balcázar, M.; Arjona, N. Electrochemical valorization of crude glycerol in alkaline medium for energy conversion using $\mathrm{Pd}, \mathrm{Au}$ and PdAu nanomaterials. Fuel 2020, 262, 116556.

(44) Habibi, E.; Razmi, H. Glycerol electrooxidation on Pd, Pt and $\mathrm{Au}$ nanoparticles supported on carbon ceramic electrode in alkaline media. Int. J. Hydrog. Energy 2012, 37, 16800-16809.

(45) Zhang, J. H.; Liang, Y. J.; Li, N.; Li, Z. Y.; Xu, C. W.; Jiang, S. P. A remarkable activity of glycerol electrooxidation on gold in alkaline medium. Electrochim. Acta 2012, 59, 156-159.

(46) Borkowska, Z.; Tymosiak-Zielinska, A.; Shul, G. Electrooxidation of methanol on polycrystalline and single crystal gold electrodes. Electrochim. Acta 2004, 49, 1209-1220.

(47) Zhang, Y.; Wang, J. G.; Yu, X.; Baer, D. R.; Zhao, Y.; Mao, L.; Wang, F.; Zhu, Z. Potential-dynamic surface chemistry controls the electrocatalytic processes of ethanol oxidation on gold surfaces. ACS Energy Lett. 2019, 4, 215-221.

(48) Ide, M. S.; Davis, R. J. The important role of hydroxyl on oxidation catalysis by gold nanoparticles. Acc. Chem. Res. 2014, 47, $825-833$.

(49) Chibani, S.; Michel, C.; Delbecq, F.; Pinel, C.; Besson, M. On the key role of hydroxyl groups in platinum-catalysed alcohol oxidation in aqueous medium. Catal. Sci. Technol. 2013, 3, 339-350.

(50) Gu, Q.; Sautet, P.; Michel, C. Unraveling the role of base and catalyst polarization in alcohol oxidation on $\mathrm{Au}$ and $\mathrm{Pt}$ in water. ACS Catal. 2018, 8, 11716-11721.

(51) Shi, X.; Simpson, D. E.; Roy, D. The role of chemisorbed hydroxyl species in alkaline electrocatalysis of glycerol on gold. Phys. Chem. Chem. Phys. 2015, 17, 11432-11444.

(52) Avramov-Ivić, M.; Leger, J.; Lamy, C.; Jović, V.; Petrović, S. The electro-oxidation of glycerol on the gold(100)-oriented singlecrystal surface and poly crystalline surface in $0.1 \mathrm{M} \mathrm{NaOH}$. J. Electroanal. Chem. Interface Electrochem. 1991, 308, 309-317.

(53) Valter, M.; dos Santos, E. C.; Pettersson, L. G. M.; Hellman, A. Partial electrooxidation of glycerol on close-packed transition metal surfaces insights from first-principles calculations. J. Phys. Chem. C 2020, 124, 17907-17915.

(54) Li, T.; Harrington, D. A. An overview of glycerol electrooxidation mechanisms on $\mathrm{Pt}, \mathrm{Pd}$ and Au. ChemSusChem 2021, 14, $1472-1495$

(55) Fan, L.; Liu, B.; Liu, X.; Senthilkumar, N.; Wang, G.; Wen, Z. Recent progress in electrocatalytic glycerol oxidation. Energy Technol. 2021, 9, 2000804.

(56) Ketchie, W. C.; Murayama, M.; Davis, R. J. Selective oxidation of glycerol over carbon-supported AuPd catalysts. J. Catal. 2007, 250, 264-273.

(57) Yan, H.; Yao, S.; Liang, W.; Feng, X.; Jin, X.; Liu, Y.; Chen, X.; Yang, C. Selective oxidation of glycerol to carboxylic acids on $\mathrm{Pt}(111)$ in base-free medium: A periodic density functional theory investigation. Appl. Surf. Sci. 2019, 497, 143661.

(58) Hohenberg, P.; Kohn, W. Inhomogeneous electron gas. Phys. Rev. 1964, 136, B864.

(59) Kohn, W.; Sham, L. J. Self-consistent equations including exchange and correlation effects. Phys. Rev. 1965, 140, A1133.

(60) Larsen, A. H.; et al. The atomic simulation environment-A Python library for working with atoms. J. Phys.: Condens. Matter 2017, $29,273002$.

(61) Enkovaara, J.; et al. Electronic structure calculations with GPAW: A real-space implementation of the projector augmentedwave method. J. Phys.: Condens. Matter 2010, 22, 253202.

(62) Mortensen, J. J.; Hansen, L. B.; Jacobsen, K. W. Real-space grid implementation of projector augmented wave method. Phys. Rev. B 2005, 71, 035109.

(63) Blöchl, P. E. Projector augmented wave method. Phys. Rev. B 1994, 50, 17953-17979.

(64) Behravesh, E.; Melander, M. M.; Wärnå, J.; Salmi, T.; Honkala, K.; Murzin, D. Y. Oxidative dehydrogenation of ethanol on gold: Combination of kinetic experiments and computation approach to unravel the reaction mechanism. J. Catal. 2021, 394, 193-205.

(65) Perdew, J. P.; Burke, K.; Ernzerhof, M. Generalized gradient approximation made simple. Phys. Rev. Lett. 1996, 77, 3865-3868.

(66) Perdew, J. P.; Burke, K.; Ernzerhof, M. Generalized gradient approximation made simple [Phys. Rev. Lett. 77, 3865 (1996)]. Phys. Rev. Lett. 1997, 78, 1396-1397.

(67) Tkatchenko, A.; Scheffler, M. Accurate molecular van der Waals interactions from ground-state electron density and Free-Atom Reference Data. Phys. Rev. Lett. 2009, 102, 073005.

(68) Held, A.; Walter, M. Simplified continuum solvent model with a smooth cavity based on volumetric data. J. Chem. Phys. 2014, 141, 174108.

(69) Melander, M. M.; Kuisma, M. J.; Christensen, T. E. K.; Honkala, K. Grand-canonical approach to density functional theory of electrocatalytic systems: Thermodynamics of solid-liquid interfaces at constant ion and electrode potentials. J. Chem. Phys. 2019, 150, 041706.

(70) Davey, W. P. Precision measurements of the lattice constants of twelve common metals. Phys. Rev. 1925, 25, 753-761.

(71) Padayachee, D.; Golovko, V.; Ingham, B.; Marshall, A. T. Influence of particle size on the electrocatalytic oxidation of glycerol over carbon-supported gold nanoparticles. Electrochim. Acta 2014, 120, 398-407.

(72) Jónsson, H.; Mills, G.; Jacobsen, K. W. In Classical and quantum dynamics in condensed phase simulations; Berne, B. J., Ciccotti, G., Coker, D. F., Eds.; World Scientific: Singapore, 1998; pp 385-404.

(73) Henkelman, G.; Jónsson, H. Improved tangent estimate in the nudged elastic band method for finding minimum energy paths and saddle points. J. Chem. Phys. 2000, 113, 9978-9985.

(74) Henkelman, G.; Uberuaga, B. P.; Jónsson, H. A climbing image nudged elastic band method for finding saddle points and minimum energy paths. J. Chem. Phys. 2000, 113, 9901-9904.

(75) Smidstrup, S.; Pedersen, A.; Stokbro, K.; Jónsson, H. Improved initial guess for minimum energy path calculations. J. Chem. Phys. 2014, 140, 214106

(76) Sprowl, L. H.; Campbell, C. T.; Árnadóttir, L. Hindered translator and hindered rotor models for adsorbates: Partition functions and entropies. J. Phys. Chem. C 2016, 120, 9719-9731.

(77) Campbell, C. T.; Sprowl, L. H.; Árnadóttir, L. Equilibrium constants and rate constants for adsorbates: Two-dimensional (2D) ideal gas, 2D ideal lattice gas, and ideal hindered translator models. J. Phys. Chem. C 2016, 120, 10283-10297.

(78) Nørskov, J. K.; Rossmeisl, J.; Logadottir, A.; Lindqvist, L.; Kitchin, J. R.; Bligaard, T.; Jónsson, H. Origin of the overpotential for oxygen reduction at a fuel-cell cathode. J. Phys. Chem. B 2004, 108, 17886-17892.

(79) Melander, M. M. Grand canonical rate theory for electrochemical and electrocatalytic systems I: general formulation and 
proton-coupled electron transfer reactions. J. Electrochem. Soc. 2020, $167,116518$.

(80) Hansen, H. A.; Rossmeisl, J.; Nørskov, J. K. Surface Pourbaix diagrams and oxygen reduction activity of $\mathrm{Pt}, \mathrm{Ag}$ and $\mathrm{Ni}(111)$ surfaces studied by DFT. Phys. Chem. Chem. Phys. 2008, 10, 3722-3730.

(81) Kastlunger, G.; Lindgren, P.; Peterson, A. A. Controlledpotential simulation of elementary electrochemical reactions: Proton discharge on metal surfaces. J. Phys. Chem. C 2018, 122, 1277112781.

(82) Duan, Z.; Henkelman, G. Theoretical resolution of the exceptional oxygen reduction activity of $\mathrm{Au}(100)$ in alkaline media. ACS Catal. 2019, 9, 5567-5573.

(83) Heenen, H. H.; Gauthier, J. A.; Kristoffersen, H. H.; Ludwig, T.; Chan, K. Solvation at metal/water interfaces: An ab initio molecular dynamics benchmark of common computational approaches. J. Chem. Phys. 2020, 152, 144703.

(84) Verma, A. M.; Honkala, K.; Melander, M. M. Computational Screening of Doped Graphene Electrodes for Alkaline $\mathrm{CO}_{2}$ Reduction. Front. Energy Res. 2021, 8, 388.

(85) Callam, C. S.; Singer, S. J.; Lowary, T. L.; Hadad, C. M. Computational analysis of the potential energy surfaces of glycerol in the gas and aqueous phases: Effects of level of theory, basis set, and solvation on strongly intramolecularly hydrogen-bonded systems. J. Am. Chem. Soc. 2001, 123, 11743-11754.

(86) Baltrusaitis, J.; Valter, M.; Hellman, A. Geometry and electronic properties of glycerol adsorbed on bare and transition-metal surfacealloyed $\mathrm{Au}(111)$ : A density functional theory study. J. Phys. Chem. C 2016, 120, 1749-1757.

(87) Clabaut, P.; Schweitzer, B.; Götz, A. W.; Michel, C.; Steinmann, $S$. N. Solvation free energies and adsorption energies at the metal/ water interface from hybrid quantum-mechanical/molecular mechanics simulations. J. Chem. Theor. Comp. 2020, 16, 6539-6549.

(88) Pfisterer, J. H. K.; Nattino, F.; Zhumaev, U. E.; Breiner, M.; Feliu, J. M.; Marzari, N.; Domke, K. F. Role of $\mathrm{OH}$ intermediates during the $\mathrm{Au}$ oxide electro-reduction at low $\mathrm{pH}$ elucidated by electrochemical surface-enhanced Raman spectroscopy and implicit solvent density functional theory. ACS Catal. 2020, 10, 12716-12726.

(89) Schmidt, P. S.; Thygesen, K. S. Benchmark database of transition metal surface and adsorption energies from many-body perturbation theory. J. Phys. Chem. C 2018, 122, 4381-4390.

(90) Nair, A. S.; Pathak, B. Accounting for dispersion effects in DFT framework of electrocatalysis: A case study of solvent mediated oxygen reduction reaction. ChemRxiv 2021, DOI: 10.33774/chemrxiv-2021-4pq0b.

(91) Hörmann, N. G.; Marzari, N.; Reuter, K. Electrosorption at metal surfaces from first principles. Npj Comput. Mater. 2020, 6, 136.

(92) Angelucci, C. A.; Varela, H.; Tremiliosi-Filho, G.; Gomes, J. F. The significance of non-covalent interactions on the electro-oxidation of alcohols on $\mathrm{Pt}$ and $\mathrm{Au}$ in alkaline media. Electrochem. Commun. 2013, 33, 10-13.

(93) Nakamura, M.; Nakajima, Y.; Kato, K.; Sakata, O.; Hoshi, N. Surface oxidation of $\mathrm{Au}(111)$ electrode in alkaline media studied by using X-ray diffraction and infrared spectroscopy: Effect of alkali metal cation on the alcohol oxidation reactions. J. Phys. Chem. C 2015, 119, 23586-23591.

(94) Porta, F.; Prati, L. Selective oxidation of glycerol to sodium glycerate with gold-on-carbon catalyst: An insight into reaction selectivity. J. Catal. 2004, 224, 397-403.

(95) Pakrieva, E.; Kolobova, E.; German, D.; Stucchi, M.; Villa, A.; Prati, L.; Carabineiro, S. A.; Bogdanchikova, N.; Cortés Corberán, V.; Pestryakov, A. Glycerol oxidation over supported gold catalysts: The combined effect of Au particle size and basicity of support. Processes 2020, 8, 1016

(96) Spendelow, J. S.; Wieckowski, A. Electrocatalysis of oxygen reduction and small alcohol oxidation in alkaline media. Phys. Chem. Chem. Phys. 2007, 9, 2654-2675.

(97) Yang, L.; Li, X.; Chen, P.; Hou, Z. Selective oxidation of glycerol in a base-free aqueous solution: A short review. Chin. J. Catal. 2019, 40, 1020-1034.
(98) Fu, J.; He, Q.; Miedziak, P. J.; Brett, G. L.; Huang, X.; Pattisson, S.; Douthwaite, M.; Hutchings, G. J. The Role of $\mathrm{Mg}(\mathrm{OH}) 2$ in the So-Called "Base-Free" Oxidation of Glycerol with AuPd Catalysts. Chem.-Eur. J. 2018, 24, 2396-2402.

(99) Yuan, Z.; Gao, Z.; Xu, B. Q. Acid-base property of the supporting material controls the selectivity of Au catalyst for glycerol oxidation in base-free water. Chin. J. Catal. 2015, 36, 1543-1551.

(100) Wojcieszak, R.; Ferraz, C. P.; Sha, J.; Houda, S.; Rossi, L. M.; Paul, S. Advances in base-free oxidation of bio-based compounds on supported gold catalysts. Catalysts 2017, 7, 352.

(101) Ferraz, C. P.; Zieliński, M.; Pietrowski, M.; Heyte, S.; Dumeignil, F.; Rossi, L. M.; Wojcieszak, R. Influence of Support Basic Sites in Green Oxidation of Biobased Substrates Using Au-Promoted Catalysts. ACS Sustain. Chem. Eng. 2018, 6, 16332-16340.

(102) de Souza, N. E.; Gomes, J. F.; Tremiliosi-Filho, G. Reactivity of 3-carbon-atom chain alcohols on gold electrode: A comparison to understand the glycerol electro-oxidation. J. Electroanal. Chem. 2017, 800, 106-113. Special Issue in honor of Masatoshi Osawa

(103) Attia, S.; Schmidt, M. C.; Schröder, C.; Schauermann, S. Formation and stabilization mechanisms of enols on $\mathrm{Pt}$ through multiple hydrogen bonding. ACS Catal. 2019, 9, 6882-6889.

(104) Exner, K. S. Design criteria for oxygen evolution electrocatalysts from first principles: Introduction of a unifying materialscreening Approach. ACS Appl. Energy Mater. 2019, 2, 7991-8001.

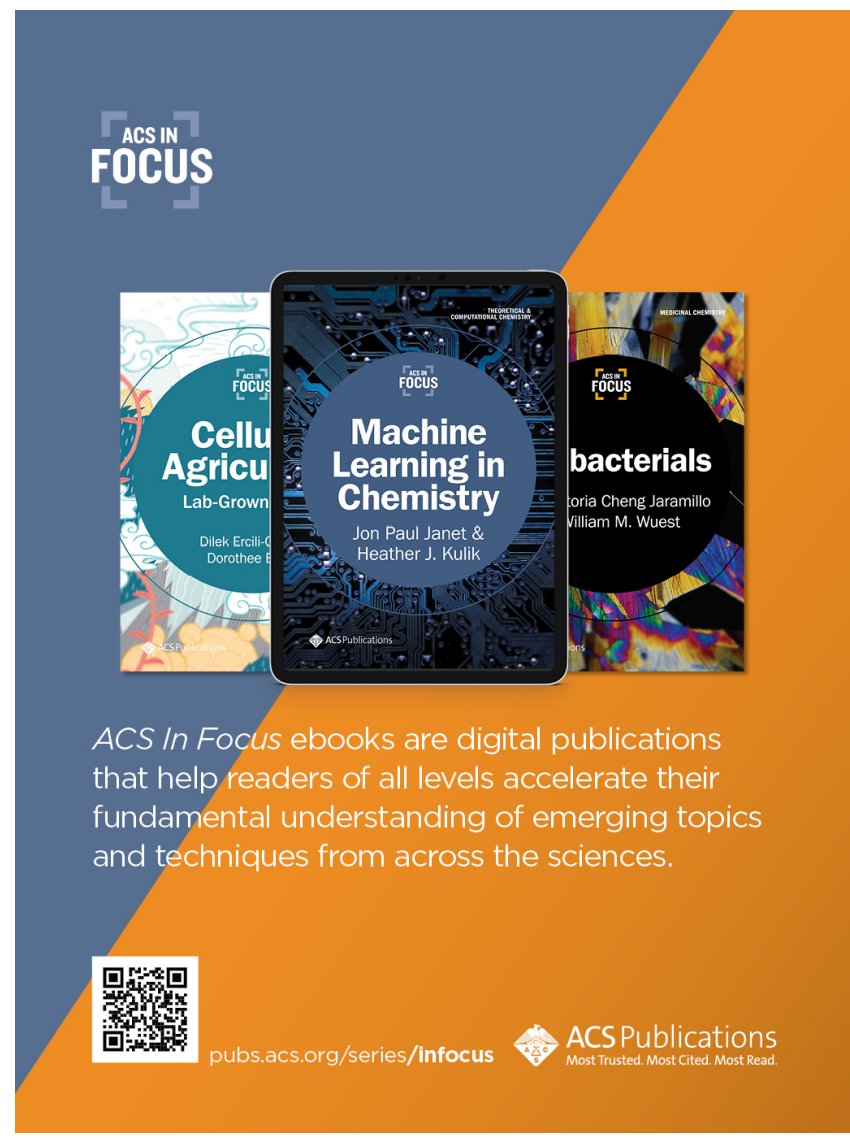

